\title{
Article \\ Energy Cane $x$ Sugarcane Microregion Interaction in the State of Pernambuco: Sugarcane for Production of Bioenergy and Renewable Fuels
}

\author{
João de Andrade Dutra Filho ${ }^{1, * \mathbb{C}}$, Frank Gomes-Silva ${ }^{2}$, Lauter Silva Souto ${ }^{3}$, Anielson dos Santos Souza ${ }^{3}$, \\ Rômulo Gil de Luna ${ }^{3}$, Guilherme Rocha Moreira ${ }^{2}$, Moacyr Cunha Filho ${ }^{2}$, Marcelo Cleon de Castro Silva ${ }^{3}$, \\ Andréa Chaves Fiuza Porto ${ }^{4}\left(\mathbb{D}\right.$, Cícero Carlos Ramos de Brito ${ }^{5}$, Mária Lindomárcia Leonardo da Costa ${ }^{6}$, \\ Odair Honorato de Oliveira ${ }^{7}$ (D), Amaro Epifânio Pereira Silva ${ }^{8}$, Fabiana Aparecida Cavalcante Silva ${ }^{9}$, \\ André Luiz Pinto dos Santos ${ }^{2}$ and Tercilio Calsa Júnior ${ }^{10}$
}

1 Biological Science Nucleus, Vitoria Academic Center, Federal University of Pernambuco, Rua Alto do Reservatório, s/n-Bela Vista, Vitória de Santo Antão 55608-680, Pernambuco, Brazil

2 Department of Statistics and Informatics, Federal Rural University of Pernambuco, Rua Dom Manuel de Medeiros, s/n-Dois Irmãos, Recife 52171-900, Pernambuco, Brazil; franksinatrags@gmail.com (F.G.-S.); guirocham@gmail.com (G.R.M.); moacyr.cunhafo@ufrpe.br (M.C.F.); andredefensor@hotmail.com (A.L.P.d.S.)

check for

updates

Citation: Dutra Filho, J.d.A.; Gomes-Silva, F.; Souto, L.S.; Souza, A.d.S.; de Luna, R.G.; Moreira, G.R.; Filho, M.C.; Silva, M.C.d.C.; Fiuza Porto, A.C.; de Brito, C.C.R.; et al. Energy Cane $x$ Sugarcane Microregion Interaction in the State of Pernambuco: Sugarcane for Production of Bioenergy and Renewable Fuels. Agronomy 2021, 11 , 1046. https://doi.org/10.3390/ agronomy11061046

\section{Academic Editors:}

Catalina Egea-Gilabert, Mario

A. Pagnotta and Pasquale Tripodi

Received: 10 April 2021

Accepted: 20 May 2021

Published: 24 May 2021

Publisher's Note: MDPI stays neutral with regard to jurisdictional claims in published maps and institutional affiliations.

Copyright: (๑) 2021 by the authors. Licensee MDPI, Basel, Switzerland. This article is an open access article distributed under the terms and conditions of the Creative Commons Attribution (CC BY) license (https:// creativecommons.org/licenses/by/ $4.0 /)$.
3 Agri-Food Science and Technology Center, Federal University of Campina Grande, Rua Jairo Vieira Feitosa, 1770-Pereiros, Pombal 58840-000, Paraiba, Brazil; lautersouto@yahoo.com.br (L.S.S.); anielsonsantos@gmail.com (A.d.S.S.); romulo.gil.luna@gmail.com (R.G.d.L.); mdecastro70@yahoo.com.br (M.C.d.C.S.)

4 Dom Agostinho Ikas Agricultural College, Federal Rural University of Pernambuco, Avenida Dr. Francisco Corrêa, 643-Centro, São Lourenço da Mat 54735-000, Pernambuco, Brazil; achavesfiuza@yahoo.com.br

5 Federal Institute of Pernambuco, Avenida Professor Luiz Freire, 500, Cidade Universitária, Recife 50740-545, Pernambuco, Brazil; cicerocarlosbrito@yahoo.com.br

6 Animal Science Department, Federal University of Paraiba, 12 Rodovia, PB-079, Areia 58397-000, Paraiba, Brazil; lindomarciacosta@gmail.com

7 Department of Agrarian Science, Federal University of Grande Dourados, R. João Rosa Góes, 1761-Vila Progresso, Dourados 79825-070, Mato Grosso, Brazil; odairhonorato2020@gmail.com

8 Carpina Sugarcane Experimental Station, Federal Rural University of Permambuco, Rua Ângela Cristina Canto Pessoa de Luna, s/n, Carpina 55810-700, Pernambuco, Brazil; epifanioA@hotmail.com

9 Phytosanitary Diagnosis Laboratory, Northeast Strategic Technologies Center, Avenida Professor Luís Freire, 1, Cidade Universitária, Recife 50740-545, Pernambuco, Brazil; fabiana.acs@gmail.com

10 Department of Genetics, Biosciences Center, Federal University of Pernambuco, Avenida Professor Moraes Rego, 1235, Cidade Universitária, Recife 50670-901, Pernambuco, Brazil; terciliojr@yahoo.com.br

* Correspondence: joao.dutrafilho@ufpe.br

\begin{abstract}
Assessing the differential behavior of a group of genotypes in various environments is fundamentally important in any breeding program. As sugarcane is the most important crop in the state of Pernambuco, it is of great relevance to study its performance in different cultivation sites to assist in the recommendation of new cultivars that increase the productivity of the cane fields. In view of the new demand from the sugar-energy sector for cultivars with high energy potential, this work aimed to select and recommend new genotypes with high fiber and sucrose percentage in the sugarcane microregions of the state of Pernambuco. The methodologies used to classify genotypes for adaptability and stability were as follows: simple linear regression, the modified centroid method, additive main effects, multiplicative interaction analysis, and linear mixed models. Genotypes with higher productivity and specific adaptability to the tested microregions were identified. The methodologies applied were efficient and complementary in recommending genotypes with favorable prospects for increasing sugar productivity, cogeneration of electric energy and the production of renewable fuels. Genotypes $6,7,9,14,16$, and 18 stand out in terms of the productivity of sugar and fiber, with high potential to be released as commercial cultivars.
\end{abstract}

Keywords: genotype $\times$ environment interaction; high yield potential; local varieties; statistical models; prediction models; stability traits; Saccharum spp. 


\section{Introduction}

The sugarcane sector in Brazil has undergone profound changes in recent years due to the high demand of the population for clean and renewable energy [1]. There is a growing concern with environmental issues, mainly in combating the greenhouse effect from the use of so-called renewable fuels [2].

In this context, sugarcane, historically used in the production of sucrose and ethanol, now receives a new label: energy cane. This, in addition to being used in the manufacture of these traditional products, is also used in the production of second-generation ethanol and in the cogeneration of electric energy through the burning of bagasse that is ultimately the fiber of its stalks [3,4].

The need for new sugarcane genotypes with high productivity and high energy potential has directly affected breeding programs that have directed their efforts towards the development of new materials, with high fiber and sucrose percentages that meet the need to supply an efficient energy matrix without compromising the production of traditional sugar and ethanol [5]. According to Fernandes Júnior et al. [6], the development of new genotypes with a fiber percentage around $17 \%$ and $13 \%$ of sucrose content would meet the current demand in the sugar-energy sector.

The great difficulty in the development of new genotypes with these percentages of fiber and sucrose is that they are traits of very low correlation; 0.06 according to the results presented by Silva et al. [7]. Therefore, it is costly and time-consuming to concentrate these traits with similar percentages in the selected progenies and clones. In order to be successful, several crossing campaigns and successive selection cycles would be necessary. And specifically, in the case of sugarcane, due to the various levels of ploidy, and multiple alleles segregating in the same locus, this difficulty is even greater in the initial stages of selection, with the final stages of experimentation reaching very few phenotypically similar genotypes.

As in the final stages of experimentation the genotypes are evaluated in an extensive network of environments, the interaction is usually significant, and this means that the best performance shown by a given genotype in a specific environment may not be repeated in another one $[8,9]$. In the case of very similar phenotypically materials that have undergone successive selection cycles and now constitute a small improved population with a narrow genetic base, it is essential to use more robust methodologies for the analysis of adaptability and stability, with high predictive power, capable of accurately classifying the tested environments and discriminate the genotypes based on the genotypic values of their traits [10]. Thus, the breeder can identify highly productive genotypes and recommend them with greater security to the most diverse growing environments [11,12].

The state of Pernambuco has been one of the traditional sugarcane producers in the Northeast of Brazil since the colonization period. Average productivity in this state is relatively low when compared to other producing states such as São Paulo and Minas Gerais. The main factor that hinders the increase in productivity is the severe climatic variations with irregular rains and long periods of drought, heterogeneity of soils and rugged reliefs [13]. This justifies assessing the magnitude of the genotype $\times$ environment interaction and, being significant, the breeder should use specific methodologies for the analysis of adaptability and stability in order to identify genotypes adapted to the most diverse environments.

The first major difficulty in studies of adaptability and stability is to define these terms properly, because several definitions have been given by different authors. The most accepted and used definition in several improvement works is the one suggested by Mariotti et al. [14]. These authors define adaptability as the ability of genotypes to respond favorably to improving the environment and stability the ability of genotypes to exhibit highly predictable behavior due to environmental variations.

Stability can be classified as static or dynamic. Static when the genotype presents a stable performance in different environments, with little variance between the environments [15]. According to Squilassi [16], this implies a low response to stimuli for greater 
productivity, such as fertilization and cultural treatments, which is undesirable for the producer. This is stability, in a biological sense, also known as homeostasis.

Dynamic stability refers to the ability of genotypes to present stable performance, however, when evaluated in different environments, it presents predictable behavior for each of them [15]. This is stability in the agronomic sense and is extremely important in breeding works when evaluating a large number of genotypes in environments whose interaction is significant, that is, when there is a high variance between environments [17-19]. Corroborating this understanding, Borém and Miranda [20] affirm that this concept of stability is the most recommended to be adopted when evaluating quantitative traits that are by nature very influenced by the environment. According to these authors, for most quantitative traits, genotypes respond to environmental variations with variations in the phenotype. These authors also state that static stability is related to qualitative traits such as disease resistance and pod indehiscence. Thus, the present work will use the concept of dynamic stability, as it deals with the evaluation of quantitative traits in different environments.

The second major difficulty in studies of adaptability and stability would be to define the methodology to be used, and this depends on the needs of the breeder and the experimental precision that one wishes to achieve. There are several methods to assess adaptability and stability, the difference between them is in the parameters adopted, in the biometric procedures used and in the details of their analysis [18]. When improved materials are available, it is recommended to use various methodologies to accurately discriminate them in high-variation environments.

The methodology of Eberhart and Russel [19] is based on the analysis of simple linear regression, in this the regression coefficient is the parameter used to interpret the concepts of adaptability and stability. With this methodology, it is possible to identify ideal genotypes that present specific adaptability and also those with dynamic stability through the variance of the regression deviations [20].

The centroid method [21] was developed with the objective of facilitating the recommendation of the genotypes, eliminating the simultaneous analysis of several parameters. This method is based on the comparison of the Cartesian distance between the genotypes and ideotypes, and differs from the analysis of variance in that it directs the genotypes towards environmental variance. The additive main effects and multiplicative interaction analysis (AMMI) method combines a univariate analysis of the additive effects of the genotypes with the multiplicative effect of the $\mathrm{G} \times$ A interaction. Through this methodology, it is possible to decompose the interaction and identify the genotypes that most contribute to accentuate it.

The mixed linear models (REML/BLUP) are considered an optimal method of selection and identification of stable genotypes in any number of environments. This is already a major advantage over regression methods that require a large number of environments for more accurate estimates. In addition, the harmonic mean estimated by this methodology is a parameter of genotypic adaptability and stability free of genotype $\times$ environment interaction [22].

Studies aiming at the identification of new genotypes with high fiber and sucrose percentage, adapted to the microregions that make up the sugarcane region of the state of Pernambuco, assume fundamental importance in view of the highly competitive markets and the needs of the sugar-energy sector, since there are no records, in the scientific literature, of works specifically involving this theme.

In view of the facts mentioned, this study aimed to select and recommend new sugarcane genotypes with a high fiber and sucrose percentage adapted to the edaphoclimatic conditions of the sugarcane microregions of the state of Pernambuco through different adaptability and stability analysis methodologies. 


\section{Materials and Methods}

\subsection{Plant Material and Testing Environments}

The adopted methodology consisted of field experiments using quantitative methods [23]. Five experiments were carried out in two agricultural years, 2013 and 2014, considering the crops of sugarcane plant and ratoon cane in five locations, according to the classification proposed by Koffler et al. [24]: sugarcane microregions of the North Coast (NC), North Forest (NF), South Coast (SC), South Forest (SF), and Central Region of the State of Pernambuco (Table 1).

Table 1. Environment's description, geographic coordinates of test locations and general data on experimental conditions.

\begin{tabular}{|c|c|c|c|c|c|c|c|c|c|}
\hline Env & $\begin{array}{c}\text { Altitude } \\
\text { M }\end{array}$ & $\begin{array}{c}\text { Temperature } \\
{ }^{\circ} \mathrm{C}\end{array}$ & $\begin{array}{l}\text { Soil } \\
\text { Type }\end{array}$ & $\begin{array}{c}\text { Latitude } \\
{ }^{\circ} \mathrm{S}\end{array}$ & $\begin{array}{c}\text { Longitude } \\
{ }^{\circ} W\end{array}$ & $\begin{array}{c}\text { Harvest } \\
\text { Cycle }\end{array}$ & $\begin{array}{l}\text { Planting } \\
\text { Date }\end{array}$ & $\begin{array}{c}\text { Harvest } \\
\text { Date }\end{array}$ & $\begin{array}{c}\text { Total RI } \\
\text { mm }\end{array}$ \\
\hline 1.North & \multirow{2}{*}{13} & 25.4 & \multirow{2}{*}{ Spodosols } & \multirow{2}{*}{$07^{\circ} 33^{\prime} 38^{\prime \prime}$} & \multirow{2}{*}{$35^{\circ} 00^{\prime} 09^{\prime \prime}$} & Plant & $10 / 09 / 13$ & $12 / 09 / 14$ & 2300 \\
\hline Coast & & S: $25-32$ & & & & Ratoon & $12 / 09 / 14$ & $14 / 09 / 15$ & 1700 \\
\hline 2.North & \multirow[b]{2}{*}{98} & 25.2 & \multirow{2}{*}{ Ultisols } & \multirow{2}{*}{$07^{\circ} 24^{\prime} 25^{\prime \prime}$} & \multirow{2}{*}{$35^{\circ} 16^{\prime} 28^{\prime \prime}$} & Plant & $28 / 08 / 13$ & $30 / 08 / 14$ & 673 \\
\hline Forest & & S: $25-30$ & & & & Ratoon & $30 / 08 / 14$ & $30 / 08 / 15$ & 1035 \\
\hline 3.South & \multirow{2}{*}{5} & 25.6 & \multirow{2}{*}{ Oxisols } & \multirow{2}{*}{$8^{\circ} 39^{\prime} 50^{\prime \prime}$} & \multirow{2}{*}{$35^{\circ} 09^{\prime} 32^{\prime \prime}$} & Plant & $05 / 08 / 13$ & $03 / 08 / 14$ & 1900 \\
\hline Coast & & S: $25-31$ & & & & Ratoon & $06 / 08 / 14$ & $08 / 08 / 15$ & 1950 \\
\hline 4.South & \multirow{2}{*}{129} & 27 & \multirow{2}{*}{ Ultisols } & \multirow{2}{*}{$08^{\circ} 19^{\prime} 53^{\prime \prime}$} & \multirow{2}{*}{$35^{\circ} 21^{\prime} 15^{\prime \prime}$} & Plant & $10 / 08 / 13$ & $12 / 08 / 14$ & 2085 \\
\hline Forest & & S: $26-30$ & & & & Ratoon & $12 / 08 / 14$ & $14 / 08 / 15$ & 1827 \\
\hline 5.Central & \multirow{2}{*}{183} & 26 & \multirow{2}{*}{ Ultisols } & \multirow{2}{*}{$07^{\circ} 56^{\prime} 10^{\prime \prime}$} & \multirow{2}{*}{$35^{\circ} 17^{\prime} 25^{\prime \prime}$} & Plant & $03 / 09 / 13$ & $05 / 09 / 14$ & 973 \\
\hline Region & & S: $26-33$ & & & & Ratoon & $05 / 09 / 14$ & $08 / 09 / 15$ & 967 \\
\hline
\end{tabular}

Env: environments. RI: Rainfall index. Total rainfall index was obtained from the sum of the monthly indices in the cycles of sugarcane plant (2013/2014) and ratoon cane $(2014 / 2015)$. S: Summer.

Each experiment was constituted by 20 elite genotypes: 18 of them were the promising clones, from the final phases of experimentation of the Sugarcane Genetic Improvement Program of the Universidade Federal Rural de Pernambuco; member of the Interuniversity Network for the Development of the Sugar and Energy Sector (PMGCA/UFRPE/RIDESA). Meanwhile, the remaining two were the standard cultivars RB867515 and RB92579.

We opted to use the average of two agricultural years, to emphasize the analyzes of adaptability and stability in the evaluated micro-regions, since the variations observed between different environments are more accentuated (Table 1). Such a procedure is commonly performed in works with sugarcane [8].

\subsection{Experimental Design and Cultural Practices}

At each location and production system, each experiment was arranged in a randomized complete block design with four replications (block). Planting dates varied with locations and with the production system within each location (Table 1). Each experimental unit (genotypes) consisted of five grooves of $8 \mathrm{~m}$ that were $1 \mathrm{~m}$ away from each other.

Soil $\mathrm{pH}$ corrections and fertilization of the field were carried out according to the sugarcane production system [25].

\subsection{Data Collection}

In each environment, experimental unit (genotypes) were harvested at 12 months after sowing date. At the time of harvest, the traits evaluated, considering the average, in two harvest cycles (plant crop and 1st ratoon crop) were: tons of sucrose per hectare (TSH), fiber percentage (FP), sucrose percentage (SP), and tons of fiber per hectare (TFH).

Tons of sucrose per hectare (TSH) and tons of fiber per hectare (TFH) were obtained by the expressions:

$$
\mathrm{STH}=(\text { Total weight experimental plots } \times 10) / \text { plots area } \mathrm{em} \mathrm{m}^{2} ;
$$

$$
\begin{aligned}
& \mathrm{TSH}=(\mathrm{STH} \times \mathrm{SP}) / 100 ; \\
& \mathrm{TFH}=(\mathrm{STH} \times \mathrm{FP}) / 100 .
\end{aligned}
$$


Fiber and apparent sucrose percentage were estimated in laboratory by the methodology presented by Fernandes [25].

\subsection{Statistical Analysis}

The mixed models (REML/BLUP) procedure was performed to estimate the variance components and to predict the genetic values, according to the method used by Resende [22].

For deviance analysis (ANADEV) considering the average of two harvest cycles, the model used was: $\mathrm{y}=\mathrm{Xr}+\mathrm{Zg}+\mathrm{Wi}+\mathrm{e}$

where:

$\mathrm{y}$ is the data vector, $\mathrm{r}$ is effect vector of repetitions (fixed) added to general average, $\mathrm{g}$ is genotypes effect vector (aleatory), $\mathrm{i}$ is the effect vector of genotype $\times$ environment interaction (aleatory) and e is the residual vectors (aleatory). The capital letters represent incidence matrices for the cited effects. The vector $r$ contemplates all repetitions from all locations (adjust repetition-local combinations). In this case, this vector contemplates the effects of locations and repetitions within locations.

Through this model, variance components were obtained and genetic parameters.

The prediction of genotypic values, which brings together the average interaction (gem) in the different environments, is given by model: $(\hat{\mu}+\hat{g}+\hat{g} e m)$

Calculated by the equation:

$$
\hat{\mu}\left\{\left[\frac{\hat{\sigma}_{g}^{2}+\hat{\sigma}_{c}^{2}}{n}\right] \hat{\sigma}_{g}^{2}\right\} \hat{g}_{i}
$$

In which:

$\mu$ is the overall average of all environments;

$\hat{\sigma}_{g}^{2}$ is the genotypic variance;

$\hat{\sigma}_{c}^{2}$ is the variance of genotype $\times$ environment interaction;

$n$ is the number of environments; And

$\hat{g}_{i}$ is the specific genotypic effect (genotype $\mathrm{i}$ ).

2.4.1. Stability and Adaptability by Eberhart and Russel Method

In the analyzes of adaptability and stability by the method of Eberhart and Russel [19], the following linear regression model was adopted: $Y_{i j}=\beta_{o i}+\beta_{1 i} I_{j}+\delta_{i j}+\varepsilon_{i j}$

where:

$\mathrm{Y}_{\mathrm{ij}}$ : average of genotype I in environment $\mathrm{j}$;

$\beta_{\mathrm{oi}}$ : general average of genotype I;

$\beta_{1 \mathrm{i}}$ : linear regression coefficient, which measures the response of the i-th genotype to the variation of environment $j$;

$\mathrm{I}_{\mathrm{j}}$ : coded environmental index: $\sum_{\mathrm{j}} \mathrm{Ij}=0$

$\delta_{\mathrm{ij}}:$ regression deviation; and

$\varepsilon_{\mathrm{ij}}$ : average experimental error.

The averages of the genotypes and the adaptability parameter were estimated using the following equations: $\beta$ oi $=\overline{Y i}$ e $\hat{V}(\beta o i)=\frac{1}{\mathrm{e}} \hat{\sigma}_{\varepsilon}^{2}$ e $\beta 1 \mathrm{i} \frac{\sum_{\mathrm{j}} Y_{\mathrm{ijij}}}{\sum_{\mathrm{j}} \mathrm{I}_{\mathrm{j}}^{2}}$ e $\hat{\mathrm{V}}(\beta 1 \mathrm{i})=\frac{1}{\sum_{\mathrm{j}} \mathrm{I}_{\mathrm{j}}^{2}} \hat{\sigma}_{\varepsilon}^{2}$ Where: $\hat{\sigma}_{\varepsilon}^{2}=\frac{1}{\mathrm{r}} \hat{\sigma}^{2}=\frac{\operatorname{MSR}(\text { Mean square of the residue })}{\mathrm{r}(\text { Repetitions })}$

The hypothesis $H_{o}: \beta_{1 i}=1$ versus $H_{a}: \beta_{1 i} \neq 1$ was evaluated by the t-statistic, given by:

$$
t=\frac{\hat{\beta} 1 i-1}{\sqrt{\hat{V}(\hat{\beta} 1 i)}}
$$


The stability parameter $\left(\sigma_{\mathrm{di}}^{2}\right)$ was estimated by the method of analysis of variance, from the mean square of the deviation of the regression of each genotype (MSDi) and the mean square of the residue: $\sigma_{\mathrm{di}}^{2}=\frac{\sum_{\mathrm{j}} \delta_{\mathrm{ij}}^{2}}{\mathrm{e}-2}=\frac{\mathrm{MSDi}-\mathrm{MSR}}{\mathrm{r}}$ where:

e: environments;

r: repetitions

The hypothesis $\mathrm{H}_{\mathrm{o}}: \sigma_{\mathrm{di}}^{2}=0$ was evaluated by the t-statistic, given by $\mathrm{F}=\frac{\mathrm{MSDi}}{\mathrm{MSR}}$, associated with a level of significance $\alpha$ (probability of type I error) and a- 2 and $\mathrm{m}$ degrees of freedom, where $\mathrm{m}$ is the number of degrees of freedom of the residue obtained in the joint analysis.

Finally, the coefficient of determination, used as an auxiliary measure of comparison between the genotypes, was obtained by formula: $\mathrm{R}_{\mathrm{i}}^{2} \frac{\mathrm{SS}(\text { linear regression }) \mathrm{i}}{\mathrm{SS}\left(\frac{\mathrm{E}}{\mathrm{Gi}}\right)} \times 100$

From the estimate of the environmental index, the microregions were classified as favorable and unfavorable environments.

\subsubsection{Stability and Adaptability by Centroid Method}

For the application of the centroid method [21], in the analysis of adaptability and stability, the environments were classified as favorable and unfavorable according to the environmental index proposed by Finlay and Wilkinson [26] using the following equation:

$$
\mathrm{Ij}=\frac{1}{\mathrm{~g}} \sum \mathrm{iYij}-\frac{1}{\mathrm{eg}} \mathrm{L} .
$$

where:

Ij: is the coded environmental index $(\mathrm{j}=1,2, \ldots 5)$;

Yij: general average of genotype i in environment $j$;

$\mathrm{L}$ : is the total of the observations; and

e: is the number of environemnts

$\mathrm{g}$ : is the number of genotypes.

After classifying the environments, the ideotypes of differentiated response to favorable and unfavorable environments were created with the aim of classifying other points and plotting the graphs. Once the average values of the ideotypes were established, the principal component analysis was carried out, encompassing the initial g genotypes and another seven that represented the centroid in the graphic analysis, according to Cruz et al. [27]. Around these centroids, the dispersion of the other genotypes was evaluated based on the special probability measure that was calculated using the inverse of the distance between a treatment to the seven ideotypes:

$$
P_{d(i, j)}=\frac{\left(\frac{1}{d i}\right)}{\sum_{i=1}^{7} \frac{1}{d i}}
$$

where:

$\mathrm{P}_{\mathrm{d}(\mathrm{i}, \mathrm{j})}$ : is the probability of presenting a stability pattern similar to the $\mathrm{i}$-th centroid;

di: is the distance from the $i$-th point to the $j$-th centroid.

The classification of the genotypes in terms of adaptability and stability was made by comparing the values of the Cartesian distance of the genotypes in relation to the seven reference points in the graph (ideotypes or control genotypes). These were created based on the experimental data to represent: Ideotypes: I-Maximum general adaptability; II-Maximum adaptability to favorable environments; III-Maximum adaptability to unfavorable environments; IV-Little adapted; V-Average general adaptability; VI-Medium adaptability to favorable environments; and VII-Average adaptability to unfavorable environments. 


\subsubsection{Stability and Adaptability by AMMI Method}

In the analysis of adaptability and stability by the AMMI method [28], the model used was: $\bar{Y} i j=\mu+g_{i}+a_{j}+\sum_{k=1}^{n} \lambda_{k} \alpha_{j k} y_{i k}+r_{i j}+\varepsilon_{i j}$

where: $\bar{Y}_{i j}$ : is the average response of genotype $i$ in environment $j$;

$\mu$ : is the overall average of the experiments;

$\mathrm{g}_{\mathrm{i}}$ : is the fixed effect of genotype $\mathrm{i}$;

$a_{j}$ : is the effect of the environment $j$;

$\lambda_{\mathrm{k}}$ : singular value of the $\mathrm{k}$-th main component of the interaction (IPCA), $(\mathrm{k}=1,2, \ldots \mathrm{p}$, where $\mathrm{p}$ is the maximum number of estimated main components);

$\alpha_{\mathrm{ik}}$ : singular value of the i-th genotype in the k-th IPCA;

$y_{j k}$ : singular value of the $j$-th environment in the k-th IPCA;

$\mathrm{r}_{\mathrm{ij}}$ : residue of the interaction $\mathrm{G} \times \mathrm{A}$ or AMMI residue (noise present in the data); $\mathrm{k}$ : non-zero characteristic roots, $\mathrm{k}=\left[1,2, \ldots \min \left(\mathrm{g}^{-1}, \mathrm{e}^{-1}\right)\right]$;

$\varepsilon_{\mathrm{ij}}$ : is the experimental error.

The sum of squares of the genotype $\times$ environment interaction $\left(\mathrm{SS}_{\mathrm{GxE}}\right)$ was partitioned into $\mathrm{n}$ single axes or main components of the interaction (IPCA; Interaction Principal Component Analysis) that described the standard portion, each axis corresponding to an AMMI model. The selection of the model that best describes the interaction was carried out by the Gollob F test [29], obtained by the significance of each IPCA related to the Average MSR of the axes to be retained in the model.

\subsubsection{Stability and Adaptability by Mixed Models Method}

The joint selection, which considers the average productivity, stability, and adaptability of genotypes is determined by the Harmonic mean (HMRPGV) according to Equation: HMRPGVi $=\mathbf{n} /\left(\sum_{\mathbf{j}=1}^{\mathbf{n}} 1 / \mathbf{V g i j}\right)$,

In which:

$\mathrm{n}$ is the number of sites where genotype $\mathrm{i}$ was evaluated; and

Vgij is the genotypic value of genotype $i$, in environment $j$, expressed as the average proportion of this environment.

The HMRPGV values were multiplied by the general average of all environments (GM), which results in the same order of magnitude of the evaluated trait.

Phenotypic averages were grouped by the Scott and Knott test at 5\% probability [30]. All genetic-statistical analyzes were performed with the aid of the softwares Genes [31], Selegen [22], and R [32].

\section{Results}

\subsection{Deviance Analysis and Genetic Parameters}

The deviance analysis detected significant differences between the sugarcane genotypes in relation to all of the evaluated traits (Table 2).

In all of the evaluated traits, the values of the genotypic variance were not superior to the variance of the genotype $x$ environment interaction and the environment variance. The coefficient of determination of the effects of the genotype $\times$ environment interaction revealed a large participation of non-genetic variances in the phenotypic variance of the traits.

The genotypic correlation coefficients between the performance of the genotypes in the tested environments were low for the traits TSH, FP, and TFH, and moderate for SP. The coefficient of experimental variation had values classified as low in the traits FP and SP, and average in the traits TSH and TFH. The heritability of individual plots was low in magnitude. However, the average heritability of the genotypes showed high magnitude for all of the traits. 
Table 2. General average, estimates of the variance components and genetic parameters of the traits tons of sucrose per hectare (TSH), fiber percentage (FP), sucrose percentage (SP) and tons of fiber per hectare (TFH) of the sugarcane genotypes, evaluated in experiments conducted in the five sugarcane microregions of the state of Pernambuco, considering two harvest cycles.

\begin{tabular}{|c|c|c|c|c|}
\hline \multirow[b]{2}{*}{ Genetic Parameters } & \multicolumn{4}{|c|}{ Traits } \\
\hline & TSH (t.ha $\left.{ }^{-1}\right)$ & FP (\%) & SP (\%) & TFH (t.ha $\left.{ }^{-1}\right)$ \\
\hline $\mathrm{G}_{\mathrm{V}}$ & 1.24 & 0.15 & 0.21 & 1.18 \\
\hline $\mathrm{V}_{\mathrm{INT}}$ & 3.91 & 0.62 & 0.46 & 3.37 \\
\hline EV & 3.82 & 0.95 & 0.85 & 3.27 \\
\hline PV & 8.98 & 1.73 & 1.53 & 7.83 \\
\hline $\mathrm{R}^{2} \mathrm{INT}$ & 0.44 & 0.36 & 0.30 & 0.43 \\
\hline Rgloc & 0.24 & 0.19 & 0.31 & 0.26 \\
\hline $\mathrm{h}_{2 \mathrm{~g}}$ & 0.14 & 0.08 & 0.13 & 0.15 \\
\hline CVgi\% & 9.18 & 2.65 & 3.26 & 8.83 \\
\hline $\mathrm{CVe} \%$ & 16.11 & 6.69 & 6.53 & 14.68 \\
\hline $\mathrm{h}_{2 \mathrm{mg}}$ & 0.57 & 0.46 & 0.61 & 0.60 \\
\hline$A_{\text {cgen }}$ & 0.75 & 0.68 & 0.78 & 0.76 \\
\hline $\operatorname{Pr}$ & - & 0.58 & 0.58 & - \\
\hline Overall average & 12.13 & 14.57 & 14.18 & 12.32 \\
\hline Effect & \multicolumn{4}{|c|}{ Deviances } \\
\hline Genotypes & $1120.07^{* *}$ & $556.54 * *$ & $509.14^{* *}$ & $1062.36^{* *}$ \\
\hline
\end{tabular}

Tabulated Qui-quadrado $\left(X^{2}\right)$ values: 3.84 and 6.63 for the significance level of $5 \%$ and $1 \%\left({ }^{* *}\right)$ of probability, respectively, and $\left({ }^{\mathrm{ns}}\right)$ non-significant. $\mathrm{G}_{\mathrm{V}}$ : Genotypic variance. $\mathrm{V}_{\mathrm{INT}}$ : Variance of the genotype $\times$ environment interaction. $E_{V}$ : Environment variance. $P_{V}$ : Individual phenotypic variance. $R^{2}{ }_{I N T}$ : Coefficient for determining the effects of genotype $\times$ environment interaction. Rgloc: genotypic correlation between performance in different environments. $h_{2 g}$ : Heritability of individual plots in the broad sense. CVgi\%: coefficient of genotypic variation $\mathrm{CVe} \%$ : coefficient of experimental variation. $\mathrm{h}_{2 \mathrm{mg}}$ : average heritability of genotypes. Acgen: accuracy of genotype selection. Pr: phenotypic correlation between fiber percentage and sucrose percentage.

\subsection{Environments Stratification and Prediction of Genetic Values}

The analysis of stratification of environments allowed the identification of groups whose interaction was not significant (Table 3).

Table 3. Stratification of sugarcane microregions in the state of Pernambuco, Brazil, based on the similarity pattern of response of genotypes, for each environment.

\begin{tabular}{ccccc}
\hline Traits & MSI/r & F Calculated & F Tabulated (5\%) & Environments \\
\hline TSH & - & - & - & - \\
FP & 0.31 & 1.29 & 1.44 & 3,5 and 1 \\
SP & 0.26 & 1.24 & 1.62 & 2 and 5 \\
TFH & 0.88 & 1.07 & 1.62 & 3 and 4
\end{tabular}

For the TSH trait there was no group formation with the non-significant genotype $\times$ environment interaction.

It appears that for the trait FP, the genotypes showed no significant interaction with the micro regions of the South Coast, Central Region, and North Coast respectively. For the trait $\mathrm{SP}$, the genotypes showed no significant interaction in the North Forest and Central Region microregions. For the TFH trait, the genotypes showed no significant interaction with the South Coast and Região Cental microregions. For the TSH trait, there was no formation of groups of environments with non-significant interaction. These results corroborate the need to carry out analyzes of adaptability and stability of the respective genotypes in the evaluated environments.

The prediction of genetic gains is presented in Table 4. In this analysis, the genotypic effect corresponds to the real value of the genotype. $(\mu+\mathrm{g})$ is the predicted genotypic effect. The genetic gain is estimated considering the heritability parameter that would be the inheritable proportion of the genetic variability of each trait. The expression (predicted genotypic effect-genotypic effect + genetic gain) provides the new mean that corresponds 
to the expected value of the selected genotypes when grown in the respective tested environments.

Table 4. Prediction of genetic gains for the traits tons of sucrose per hectare (TSH), fiber percentage (FP), sucrose percentage (SP), and tons of fiber per hectare (TFH) in the best sugarcane genotypes, evaluated in an experiment conducted in the five sugarcane microregions of the State of Pernambuco.

\begin{tabular}{|c|c|c|c|c|}
\hline \multicolumn{5}{|c|}{ Tons of Sucrose per Hectare $\left(\mathrm{TSH} /\right.$ t.ha $\left.^{-1}\right)$} \\
\hline Genotype & Genotypic Effect & $(\mu+g)$ & Genetic Gain & New Average \\
\hline 16 & 1.41 & 13.55 & 1.41 & 13.55 \\
\hline 12 & 1.14 & 13.28 & 1.28 & 13.42 \\
\hline 9 & 0.76 & 12.90 & 1.11 & 13.24 \\
\hline 14 & 0.76 & 12.90 & 1.02 & 13.16 \\
\hline 18 & 0.74 & 12.88 & 0.96 & 13.10 \\
\hline 6 & 0.54 & 12.67 & 0.89 & 13.03 \\
\hline 11 & 0.41 & 12.55 & 0.82 & 12.96 \\
\hline 7 & 0.31 & 12.45 & 0.76 & 12.90 \\
\hline 15 & 0.26 & 12.40 & 0.70 & 12.84 \\
\hline 17 & 0.03 & 12.16 & 0.64 & 12.77 \\
\hline
\end{tabular}

Fiber Percentage (FP\%)

\begin{tabular}{ccccc}
\hline Genotype & Genotypic Effect & $(\boldsymbol{\mu}+\mathbf{g})$ & Genetic Gain & New Average \\
\hline 13 & 0.56 & 15.14 & 0.56 & 15.14 \\
17 & 0.37 & 14.95 & 0.47 & 15.05 \\
15 & 0.32 & 14.90 & 0.42 & 15.00 \\
20 & 0.29 & 14.87 & 0.39 & 14.97 \\
16 & 0.28 & 14.86 & 0.38 & 14.95 \\
14 & 0.16 & 14.74 & 0.33 & 14.91 \\
18 & 0.10 & 14.68 & 0.30 & 14.88 \\
\hline
\end{tabular}

Sucrose Percentage (SP\%)

\begin{tabular}{|c|c|c|c|c|}
\hline Genotype & Genotypic Effect & $(\mu+g)$ & Genetic Gain & New Average \\
\hline 18 & 0.55 & 14.73 & 0.55 & 14.73 \\
\hline 19 & 0.53 & 14.72 & 0.54 & 14.72 \\
\hline 12 & 0.39 & 14.57 & 0.49 & 14.67 \\
\hline 16 & 0.38 & 14.56 & 0.46 & 14.64 \\
\hline 17 & 0.31 & 14.49 & 0.43 & 14.61 \\
\hline 15 & 0.29 & 14.47 & 0.41 & 14.59 \\
\hline 20 & 0.23 & 14.42 & 0.38 & 14.57 \\
\hline 13 & 0.15 & 14.33 & 0.35 & 14.54 \\
\hline 14 & 0.11 & 14.29 & 0.33 & 14.51 \\
\hline 6 & 0.04 & 14.22 & 0.30 & 14.48 \\
\hline \multicolumn{5}{|c|}{ Tons of Fiber per Hectare (TFH/t.ha $\left.{ }^{-1}\right)$. } \\
\hline Genotype & Genotypic Effect & $(\mu+g)$ & Genetic Gain & New Average \\
\hline 16 & 1.56 & 13.82 & 1.56 & 13.82 \\
\hline 9 & 1.02 & 13.34 & 1.26 & 13.58 \\
\hline 7 & 0.76 & 13.09 & 1.09 & 13.42 \\
\hline 14 & 0.69 & 13.01 & 0.99 & 13.32 \\
\hline 12 & 0.68 & 13.01 & 0.93 & 13.25 \\
\hline 11 & 0.43 & 12.76 & 0.85 & 13.17 \\
\hline 6 & 0.43 & 12.75 & 0.79 & 13.11 \\
\hline 18 & 0.43 & 12.75 & 0.74 & 13.07 \\
\hline 15 & 0.29 & 12.61 & 0.69 & 13.02 \\
\hline 13 & 0.17 & 12.49 & 0.64 & 12.96 \\
\hline
\end{tabular}

Considering the average performance of genotypes in different environments (Table 4), for the trait TSH, the genotypes 16 and 12 had the highest genotypic value, the highest free average of the interaction $(\mu+\mathrm{g})$, and the highest overall average, followed by genotypes 
$9,14,18,6,11,7,15$, and 17 . For the trait FP, the genotypes 13 and 17 had the highest genotypic value, the highest free average of the interaction $(\mu+\mathrm{g})$, and the highest overall average, followed by genotypes $15,20,16,14$, and 18 . For the trait $\mathrm{SP}$, the genotypes 18 and 19 had the highest genotypic value, the highest free average of the interaction $(\mu+\mathrm{g})$, and the highest overall average, followed by genotypes 12, 16, 17, 15, 20,13, 14, and 6. Finally, for the trait TFH, the genotypes 16 and 9 had the highest genotypic value, the highest free average of the interaction $(\mu+\mathrm{g})$, and the highest overall average, followed by genotypes 7 , $14,12,11,6,18,15$, and 13 .

\subsection{Stability and Adaptability Analysis}

The adaptability and stability analysis were performed considering the traits TSH and $\mathrm{TFH}$, since the payment for the production of sugarcane in Brazil is carried out considering the average price of sugar.

\subsubsection{Eberhart and Russel Method}

The parameters of adaptability and stability obtained by the methodology of Eberhart and Russel [18] are shown in Table 5.

Table 5. Adaptability and Phenotypic Stability of 20 sugarcane genotypes with respect to the traits tons of sucrose per hectare (TSH), and tons of fiber per hectare (TFH), evaluated in experiments conducted in the final stages of experimentation (FE), in the five sugarcane microregions of the State of Pernambuco, considering two harvest cycles.

\begin{tabular}{|c|c|c|c|c|c|c|c|c|}
\hline \multirow[b]{2}{*}{ Genotypes } & \multicolumn{4}{|c|}{ TSH (t.ha-1) } & \multicolumn{4}{|c|}{ TFH (t.ha-1) } \\
\hline & $\beta_{\theta}$ & $\beta_{1}$ & $\sigma_{\mathrm{di}}^{2}$ & $R^{2}(\%)$ & $\beta_{\theta}$ & $\beta_{1}$ & $\sigma_{\mathrm{di}}^{2}$ & $R^{2}(\%)$ \\
\hline 1 & $11.28 \mathrm{~b}$ & $0.51 * *$ & $0.39 \mathrm{NS}$ & 68.47 & $12.05 \mathrm{~b}$ & $0.45^{* *}$ & $-0.01 \mathrm{NS}$ & 65.75 \\
\hline 2 & $12.01 \mathrm{~b}$ & $0.58 *$ & $0.33 \mathrm{NS}$ & 74.38 & $11.69 \mathrm{~b}$ & $0.70 \mathrm{NS}$ & $-0.33 \mathrm{NS}$ & 88.27 \\
\hline 3 & $9.7 \mathrm{~b}$ & $0.45^{* *}$ & $2.35 *$ & 41.02 & $10.14 \mathrm{~b}$ & $0.31^{* *}$ & $2.25 *$ & 18.75 \\
\hline 4 & $8.71 b$ & 0.64 * & $-0.68 \mathrm{NS}$ & 94.39 & $8.79 b$ & 0.60 * & $-0.55 \mathrm{NS}$ & 91.00 \\
\hline 5 & $10.74 b$ & $0.04^{* *}$ & $-0.49 \mathrm{NS}$ & 3.78 & $11.16 \mathrm{~b}$ & $-0.17^{* *}$ & $0.35 \mathrm{NS}$ & 15.82 \\
\hline 6 & $13.1 \mathrm{a}$ & $1.18 \mathrm{NS}$ & $0.24 \mathrm{NS}$ & 92.76 & $13.06 \mathrm{a}$ & $1.02 \mathrm{NS}$ & $-0.44 \mathrm{NS}$ & 95.34 \\
\hline 7 & $12.7 \mathrm{a}$ & $0.85 \mathrm{NS}$ & $1.14 \mathrm{NS}$ & 79.17 & $13.63 a$ & $1.02 \mathrm{NS}$ & $5.27 * *$ & 56.28 \\
\hline 8 & $10.41 \mathrm{~b}$ & $-0.01^{* *}$ & $3.13^{* *}$ & 0.05 & $11.07 \mathrm{~b}$ & 0.32 * & 1.93 * & 21.27 \\
\hline 9 & $13.5 \mathrm{a}$ & $0.68 \mathrm{NS}$ & $5.23 * *$ & 45.02 & $14.06 a$ & $0.64 \mathrm{NS}$ & $3.63 * *$ & 40.54 \\
\hline 10 & $11.91 \mathrm{~b}$ & $0.48^{* *}$ & $1.44 \mathrm{NS}$ & 51.38 & $11.98 \mathrm{~b}$ & $0.35^{* *}$ & $1.60 *$ & 27.40 \\
\hline 11 & $12.87 \mathrm{a}$ & $1.47^{* *}$ & $0.10 \mathrm{NS}$ & 70.13 & $13.07 \mathrm{a}$ & $1.44^{* *}$ & $-0.61 \mathrm{NS}$ & 87.69 \\
\hline 12 & $14.18 \mathrm{a}$ & $1.05 \mathrm{NS}$ & $-0.32 \mathrm{NS}$ & 95.07 & $13.49 \mathrm{a}$ & $0.90 \mathrm{NS}$ & $-0.28 \mathrm{NS}$ & 91.98 \\
\hline 13 & $11.78 \mathrm{~b}$ & $1.38 *$ & $-0.11 \mathrm{NS}$ & 96.12 & $12.62 \mathrm{a}$ & $1.56^{* *}$ & $0.24 \mathrm{NS}$ & 94.48 \\
\hline 14 & $13.5 \mathrm{a}$ & $1.78^{* *}$ & $3.32^{* *}$ & 89.05 & $13.51 \mathrm{a}$ & $1.84 * *$ & $0.63 \mathrm{NS}$ & 94.61 \\
\hline 15 & $12.61 \mathrm{a}$ & $1.76^{* *}$ & 3.81 ** & 87.75 & $12.82 \mathrm{a}$ & $1.86^{* *}$ & $5.31^{* *}$ & 80.88 \\
\hline 16 & $14.67 \mathrm{a}$ & $1.88^{* *}$ & $-0.69 \mathrm{NS}$ & 99.34 & $14.89 \mathrm{a}$ & $2.04 * *$ & $0.44 \mathrm{NS}$ & 96.10 \\
\hline 17 & $12.19 a$ & $1.48^{* *}$ & $0.54 \mathrm{NS}$ & 94.18 & $12.29 \mathrm{a}$ & $1.00 \mathrm{NS}$ & $1.29 \mathrm{NS}$ & 78.04 \\
\hline 18 & $13.46 \mathrm{a}$ & $1.92 * *$ & $2.39 *$ & 92.37 & $13.05 a$ & $2.00 * *$ & $4.03 * *$ & 86.01 \\
\hline 19 & $11.8 \mathrm{~b}$ & $1.54^{* *}$ & $5.25^{* *}$ & 80.82 & $11.17 \mathrm{~b}$ & $1.79^{* *}$ & $3.50 * *$ & 84.79 \\
\hline 20 & $11.51 \mathrm{~b}$ & $1.24 \mathrm{NS}$ & $-0.37 \mathrm{NS}$ & 96.63 & $11.8 \mathrm{~b}$ & $1.28 \mathrm{NS}$ & $-0.52 \mathrm{NS}$ & 97.66 \\
\hline
\end{tabular}

$\mathrm{B}_{\theta}$ : Average of the genotype. ${ }^{* *}$, : significant at $1 \%$ and $5 \%$ probability of error, respectively, by the $t$ test. $\left(\mathrm{H} 0: \beta_{1 \mathrm{i}}=1,0\right)$ and by the test $\mathrm{F}$ $\left(\mathrm{H} 0: \sigma_{\mathrm{di}}^{2}=0\right)$. NS: non-significant. $\mathrm{R}^{2}(\%)$ : Coefficient of determination. Phenotypic averages followed by the same letter in the column belong to the same group by the Scott and Knott test at $5 \%$ probability.

Regarding the trait TSH, genotypes 6, 7, and 12 can be classified as ideal (high productivity, $\beta_{1}=1$ e $\sigma_{\mathrm{di}}^{2}=0$.). Genotypes $9,14,15$, and 18 are adapted to favorable environments and have low stability. Genotypes 11,16, and 17, on the other hand, are adapted to favorable environments, but have high stability. Only genotype 8 can be classified as adaptable to unfavorable environments. For the trait TFH, genotypes 6, 12, and 17 can be classified as ideal. Genotypes 11,13,14, and 16 are adapted to favorable environments and have high stability. Genotypes 7, 9, 15, and 18 are adapted to favorable environments and have low stability. Only genotypes 5 and 8 were shown to be adapted to unfavorable environments. 
An important observation that must be made in this type of analysis is that the genotypes with variance of the negative and non-significant regression deviations $\left(\sigma_{\mathrm{di}}^{2}\right)$ are due to the fact that they present an MSR that is greater than the MSDi.

\subsubsection{Centroid Method}

The classification of environments using the Centroid method is shown in Table 6.

Table 6. Classification of sugarcane microregions using environmental index (Linear regression and Centroid method) in the evaluation of 20 sugarcane genotypes for TSH and TFH.

\begin{tabular}{ccccccccc}
\hline Environments & $\begin{array}{c}\text { Average } \\
\text { TSH }\end{array}$ & $\begin{array}{c}\text { Average } \\
\text { TFH }\end{array}$ & $\mathbf{( I j ) ~ T S H}$ & $\mathbf{( I j ) ~ T F H}$ & Max TSH & Min TSH & Max TFH & Min TFH \\
\hline $\begin{array}{c}\text { 1. NC } \\
\text { (Favorable) }\end{array}$ & 12.48 & 13.14 & 0.35 & 0.82 & 17.50 & 7.73 & 17.93 & 8.63 \\
$\begin{array}{c}\text { 2. NF } \\
\text { (Unfavorable) }\end{array}$ & 8.49 & 9.30 & -3.64 & -3.02 & 12.12 & 3.91 & 12.56 & 4.04 \\
$\begin{array}{c}\text { 3. SC } \\
\text { (Favorable) }\end{array}$ & 15.90 & 14.54 & 3.76 & 2.21 & 21.99 & 10.09 & 20.24 & 9.89 \\
$\begin{array}{c}\text { 4. SF } \\
\text { (Favorable) } \\
\begin{array}{c}\text { 5. CR } \\
\text { (Unfavorable) }\end{array}\end{array}$ & 13.49 & 14.26 & 1.36 & 1.94 & 17.84 & 8.88 & 19.16 & 9.40 \\
\hline
\end{tabular}

NC: North Coast, NF: North Forest, SC: South Coast, SF: South Forest, and CR: Central Region.

Once the efficiency of this methodology was verified in the classification of the environments, it was possible to determine the position of the genotypes in two-dimensional graphs (Figure 1)

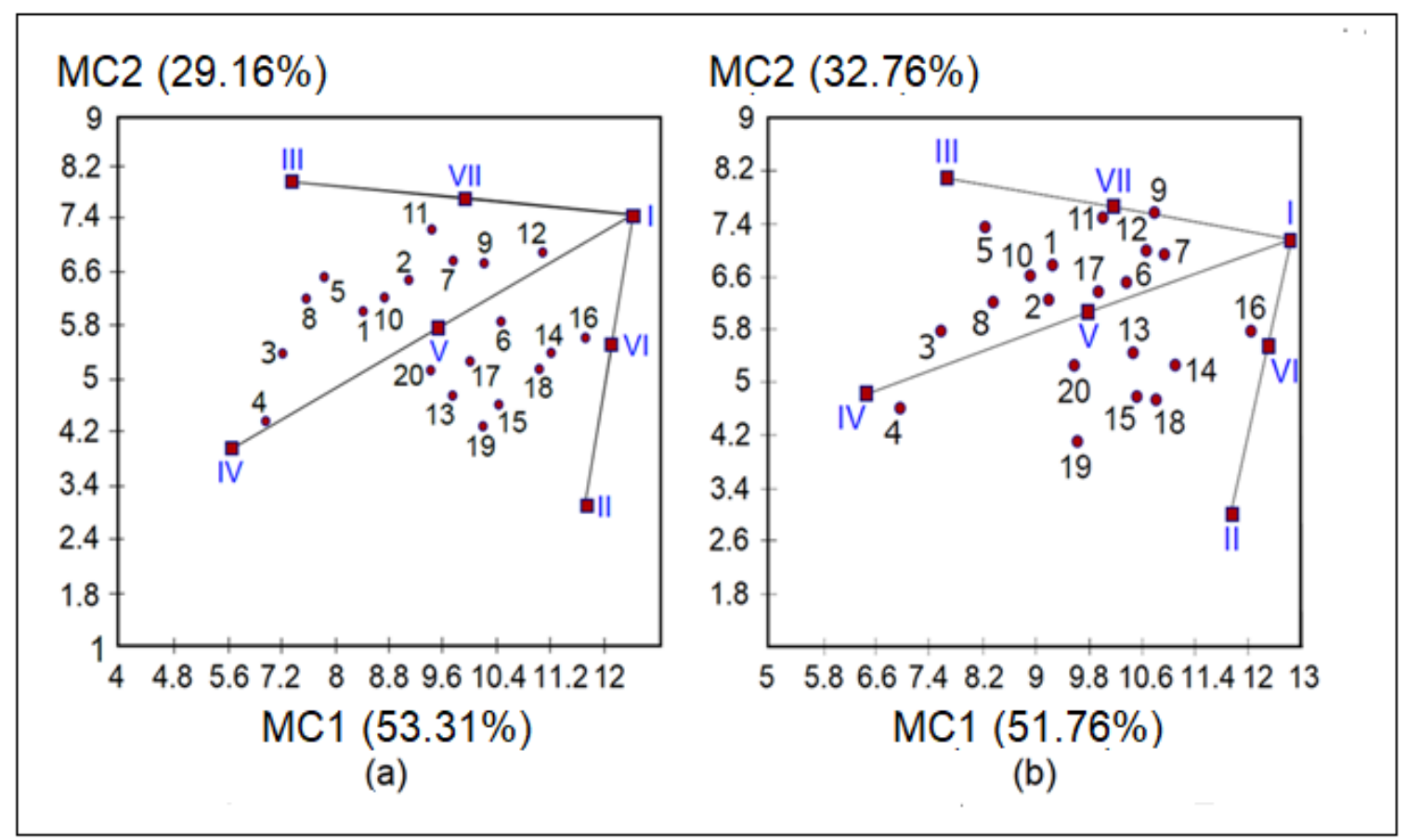

Figure 1. Graphic dispersion of the first two main components of 20 sugarcane genotypes. In (a), a graph constructed based on TSH. In (b), a graph constructed based on TFH. Ideotypes: I-Maximum general adaptability; II-Maximum adaptability to favorable environments; III-Maximum adaptability to unfavorable environments; IV—Little adapted; V-Average general adaptability; VI—Average adaptability to favorable environments; and VII-Average adaptability to unfavorable environments. 
It is possible to see, in the graphs presented, the formation of an arrow-shaped gradient to the extreme right, making it possible to identify genotypes as to the adaptability parameters.

Genotype 16, located closest to the tip of the arrow, is the most productive with medium general adaptability and genotype 4 , the most distant, is the least productive and poorly adapted for both productivity traits.

According to Nascimento et al. [33], the genotypes furthest from the straight line, and closest to the centroid, are classified as favorable and unfavorable environments. However, when the genotypes are very dispersed on the chart, around the centroid, it makes classification difficult.

\subsubsection{AMMI Method}

Analysis by the AMMI method revealed significant differences between genotypes, environments and the genotype $\times$ environment interaction (Table 7).

Table 7. Summary of the AMMI analysis of the traits tons of sucrose per hectare (TSH) and tons of fiber per hectare (TFH) in 20 sugarcane genotypes evaluated in five sugarcane microregions in the state of Pernambuco.

\begin{tabular}{|c|c|c|c|c|c|c|c|c|c|}
\hline \multirow[b]{2}{*}{ SV } & \multirow[b]{2}{*}{ DF } & \multicolumn{4}{|c|}{ TSH (t.ha-1) } & \multicolumn{4}{|c|}{ TFH (t.ha $\left.{ }^{-1}\right)$} \\
\hline & & SS & MS & $\operatorname{Exp}(\%)$ & Ac $(\%)$ & SS & MS & $\operatorname{Exp}(\%)$ & Ac $(\%)$ \\
\hline Genotype & 19 & 210.51 & $11.08^{* *}$ & & & 192.15 & $10.11^{* *}$ & & \\
\hline Environment & 4 & 656.75 & $164.18^{* *}$ & & & 446.99 & $111.74^{* *}$ & & \\
\hline $\mathrm{G} \times \mathrm{E}$ & 76 & 370.55 & $4.88^{* *}$ & & & 318.65 & $4.19^{* *}$ & & \\
\hline IPCA1 & 22 & 279.06 & $12.68^{* *}$ & 75.31 & 75.31 & 236.77 & $10.76^{* *}$ & 74.30 & 74.30 \\
\hline IPCA2 & 20 & 63.13 & $3.16^{\mathrm{ns}}$ & 17.04 & 92.35 & 54.62 & 2.73 & 17.14 & 91.44 \\
\hline IPCA3 & 18 & 17.01 & $0.94^{\mathrm{ns}}$ & 4.59 & 96.94 & 16.63 & 0.92 & 5.22 & 96.66 \\
\hline IPCA4 & 16 & 11.34 & $0.70^{\mathrm{ns}}$ & 3.06 & 100 & 10.61 & 0.66 & 3.34 & 100 \\
\hline $\begin{array}{l}\text { Mean } \\
\text { error }\end{array}$ & 150 & 382.90 & 2.55 & & & 329.27 & 2.19 & & \\
\hline
\end{tabular}

** Significant at $1 \%$ probability by the Gollob $\mathrm{F}$ test. ${ }^{\text {ns }}$ Not significant. SV: Source of variation. $\mathrm{G} \times \mathrm{E}$ : Genotype $\times$ environment interaction. IPCA: Main component shaft. DF: Degrees of freedom. SS: Sum of squares. MS: Medium squares. Exp: Explained. Ac: Accumulated.

The AMMI1 biplot built based on the performance of the genotypes in relation to the traits TSH and TFH are shown in Figure 2

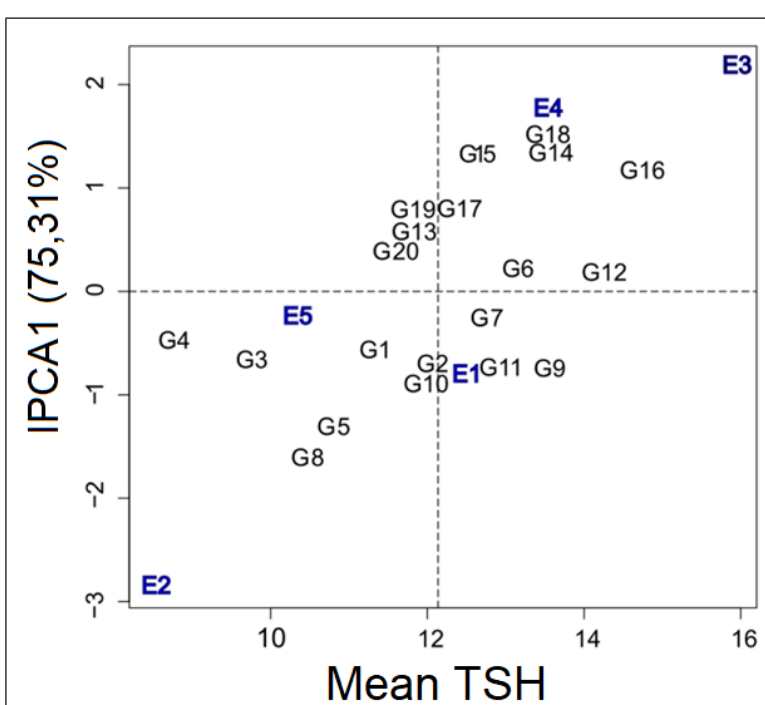

(a)

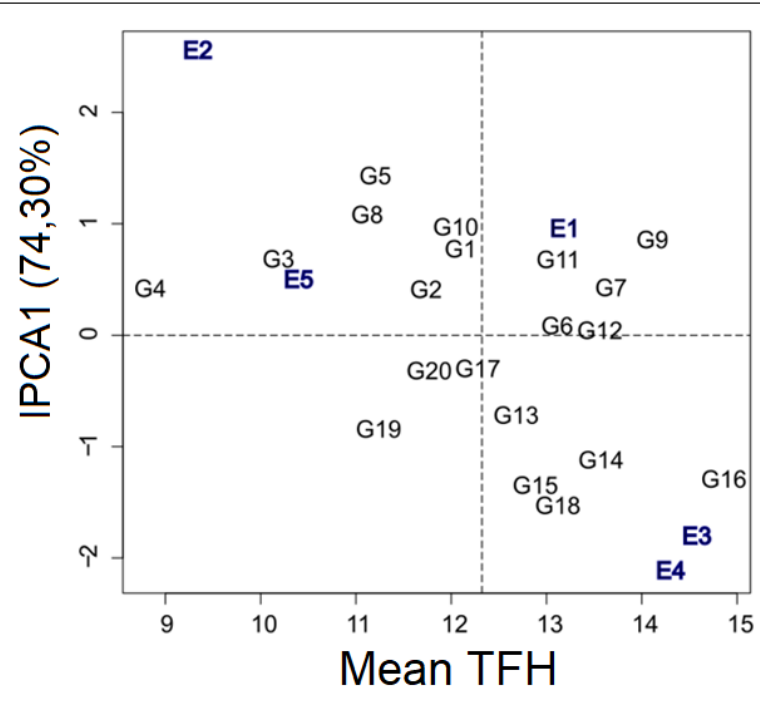

(b)

Figure 2. Biplot AMMI1 to TSH (a) e TFH (b) in 20 sugarcane genotypes evaluated in 5 sugarcane microregions in the State of Pernambuco. G: Genotype and E: Environment. 
In these graphs, the abscissas represent the main effects, that is, the general averages of TSH and TFH of the evaluated genotypes, and the ordinated represent axes of interaction IPCA1. Thus, genotypes with IPCA1 values close to zero are considered to be highly stable in the tested microregions.

Regarding TSH, genotypes 6, 7, and 12 have high phenotypic stability because they are close to the IPCA1 axis line. Genotypes 2, 9, 10, and 11 have specific adaptability to the North Coast microregion (E1), and are classified as favorable. Genotypes 14, 15, 16, and 18 have specific adaptability to the South Forest microregion (E4), and are also classified as favorable.

For TFH, genotypes 6, 12, and 17 have high stability. Genotypes 7, 9, and 11 have specific adaptability to the North Coast (E1) microregion, classified as favorable. Genotype 3 has specific adaptability to the Centro microregion (E5) classified as unfavorable. Genotypes 13,14, 15, 16, and 18 have specific adaptability to the South Coast (E3) and South Forest (E4) microregion, classified as favorable.

It is important to note that genotype 4 showed a lower average in both productivity traits, in addition to very low stability, which is recommended once again for disposal.

\subsubsection{Mixed Models Method}

The parameters of genotypic adaptability and stability (HMRPGV and HMRPGV ${ }^{*} \mathrm{GM}$ ) are presented in Table 8.

Table 8. Adaptability and stability (HMRPGV and HMRPGV *GM) of genotypic values of sugarcane genotypes, with prediction by the analysis of the best unbiased linear predictor (BLUP), evaluated in five sugarcane microregions of the State of Pernambuco, in the sugarcane and two sugarcane harvest cycles.

\begin{tabular}{|c|c|c|c|c|}
\hline \multirow[b]{3}{*}{ Genotypes } & \multicolumn{4}{|c|}{ Traits } \\
\hline & \multicolumn{2}{|c|}{ TSH } & \multicolumn{2}{|c|}{ TFH } \\
\hline & HMRPGV & HMRPGV (MG) & HMRPGV & HMRPGV (MG) \\
\hline 12 & 1.16 & 14.03 & 1.09 & 13.44 \\
\hline 16 & 1.15 & 14.01 & 1.15 & 14.25 \\
\hline 9 & 1.10 & 13.37 & 1.12 & 13.91 \\
\hline 11 & 1.06 & 12.92 & 1.06 & 13.10 \\
\hline 6 & 1.06 & 12.90 & 1.05 & 13.01 \\
\hline 14 & 1.04 & 12.69 & 1.05 & 13.00 \\
\hline 7 & 1.04 & 12.68 & 1.08 & 13.40 \\
\hline 18 & 1.04 & 12.67 & 1.00 & 12.36 \\
\hline 2 & 0.99 & 12.11 & 0.95 & 11.78 \\
\hline 10 & 0.99 & 11.97 & 0.97 & 12.01 \\
\hline 15 & 0.98 & 11.90 & 0.99 & 12.22 \\
\hline 17 & 0.97 & 11.80 & 0.99 & 12.21 \\
\hline 1 & 0.94 & 11.42 & 0.98 & 12.14 \\
\hline 13 & 0.94 & 11.42 & 0.99 & 12.26 \\
\hline 20 & 0.93 & 11.33 & 0.94 & 11.69 \\
\hline 5 & 0.90 & 10.94 & 0.91 & 11.23 \\
\hline 19 & 0.88 & 10.77 & 0.83 & 10.20 \\
\hline 8 & 0.86 & 10.50 & 0.90 & 11.17 \\
\hline 3 & 0.81 & 9.88 & 0.83 & 10.28 \\
\hline 4 & 0.74 & 9.02 & 0.73 & 9.09 \\
\hline
\end{tabular}

The genotypes $12,16,9,11,6,14,7$, and 18 are the most stables in relation to the traits TSH and TFH and higher productivity respectively.

\section{Discussion}

\subsection{Deviance Analysis and Genetic Parameters}

Significant differences detected by the deviance analysis indicate the occurrence of genetic variability between the evaluated genotypes [34]. This genetic variability is 
due to the different alleles that genotypes have in their genetic makeup. For genetic improvement, aiming at the production of sucrose, energy, and biofuels, this result is fundamentally important because it allows the artificial selection of the genotypes that presented better performance in the traits evaluated in different environments [35]. These results corroborate those obtained by Silveira et al. [36] who, evaluating 13 sugarcane genotypes in nine environments in the state of Minas Gerais, detected genetic variability and managed to select those with higher productivity and adapted to the respective cultivation environments.

High values of non-genetic variances and coefficients for determining the effects of the genotype $\times$ environment interaction indicate that the edaphoclimatic factors had a considerable influence on the phenotypic expression of the traits [37]. The low amount of rainfall was the main environmental factor that influenced the traits in the evaluated genotypes (Table 1). According to Inman-Bamber and Smith [38], sugarcane requires $1500 \mathrm{~mm}$ to $2500 \mathrm{~mm}$ of rain well distributed throughout its cycle. This did not happen in all microregions, and consequently there was no regularity in the repetition of the agroindustrial performance of the genotypes, as demonstrated by the low genotypic correlation and heritability of individual plots (Table 2).

\subsection{Environments Stratification and Prediction of Genetic Values}

Considering the influence of environmental factors, in the phenotypic expression of the traits, two important strategies must be adopted; the first would be to identify groups of environments in which the interaction with the genotypes was not significant. Table 3 shows that for the traits FP, SP, and TFH there was the formation of groups of environments whose interaction with the genotypes was not significant. The second strategy: predict genetic gain based on the averages of the genotypes, because according to Pedrozo et al. [39], when the selection is practiced in traits of low heritability, based on the averages of the genotypes, the genetic gains are increased, since the environmental effects tend to cancel each other out. If there are genetic gains, adaptability and stability analyzes are carried out.

The values of average heritability in the broad sense, where the average of genotypes in the blocks are considered, were estimated at 0.57 (TSH), 0.46 (FP), 0.61 (SP), and 0.60 (TFH) respectively (Table 2). According to Garcia and Nogueira [40], such values, $\geq 0.46$ are considered high and the genotypes have a high potential for selection with favorable prospects of significant genetic gains.

The greatest predicted genetic gains were obtained in genotypes $13,17,15,20,16$, 14, and 18 for the trait FP and in genotypes 18, 19, 12, 16, 17 15, 20, 13, 14, and 6 for the trait SP. Genotype 13 had a higher percentage of FP $15.14 \%$, while genotype 18 had a higher percentage of SP $14.74 \%$. The percentage of fiber (15.14\%) in genotype 13 was very close to that obtained by Fernandes Júnior et al. [6]. However, the percentage of sucrose was considerably higher $(14.74 \%)$. These authors obtained an overall average of $15.71 \%$ for the percentage of fiber and $12.96 \%$ for the percentage of sucrose. This difference in the SP values is due to the fact that these authors evaluate some families derived from crosses with species of Saccharum spontaneum and other materials of high rusticity and low sucrose percentage.

It is important to note that the best family selected by Fernandes Júnior et al. [6] had a fiber percentage of $17 \%$, while the percentage of apparent sucrose was $11.33 \%$. This result confirms the difficulty of simultaneously concentrating higher levels of fiber and sucrose in the superior genotypes, since these, as reported by Silva et al. [7], are traits of very low correlation (0.06). Therefore, several selection cycles are necessary to "optimize" these traits in the genotypes obtained by artificial hybridization, hence the importance of evaluating these materials in the final stages of experimentation, as they have already undergone several stages of evaluation and selection. In the present study, the correlation found between the percentages of fiber and sucrose was 0.58 . This result points to two important conclusions. The first is that successive cycles of intense selection in the initial phases of the genetic improvement of sugarcane makes it possible to concentrate these 
important traits of productivity in superior genotypes. The percentages of fiber and sucrose of the five best genotypes presented in Table 4, are genotypic averages free of the genotype $\times$ environment interaction already discounted from instability and capitalized on adaptability [34]. The second conclusion is that it is possible to target breeding programs to meet the recommendations of Tew and Cobil [41] and develop new genotypes with values close to $30 \%$ fiber, $5 \%$ sugar, and $65 \%$ water and thus more efficiently meet the two main demands of the sucrenergetic sector, the production of sugar and clean, renewable energy.

\subsection{Stability and Adaptability Analysis}

\subsubsection{Eberhart e Russel Method}

According to Dias et al. [42], the method proposed by Eberhart and Russel [19], classifies the genotypes for adaptability using the regression coefficient as a reference. It is a methodology based on simple linear regression and, therefore, genotypes with $\beta_{1}=1$ have general adaptability, $\beta_{1}>1$ specific adaptability to favorable environments and $\beta_{1}<1$ specific adaptability to unfavorable environments. With regard to stability, the variance of the regression deviations and, thus, genotypes with $\sigma_{\mathrm{di}}^{2}=0$ are of high stability and $\sigma_{\mathrm{di}}^{2}>0$ low stability. The ideal genotype is one that has high productivity, $\beta_{1}=1$ e $\sigma_{\mathrm{di}}^{2}=0$.

The data presented in Table 5, referring to TSH, allows the classification of genotypes 6,7 , and 12 as ideal, since they present greater productivity, being even allocated in group " $a$ " by the test of Scott and Knott [30], still had non-significant regression coefficients, that is, $\beta_{1}=1$, and variance of non-significant regression deviations, $\sigma_{\mathrm{di}}^{2}=0$. This means that these genotypes can be recommended for all sugarcane microregions in the state of Pernambuco (Figure 3).

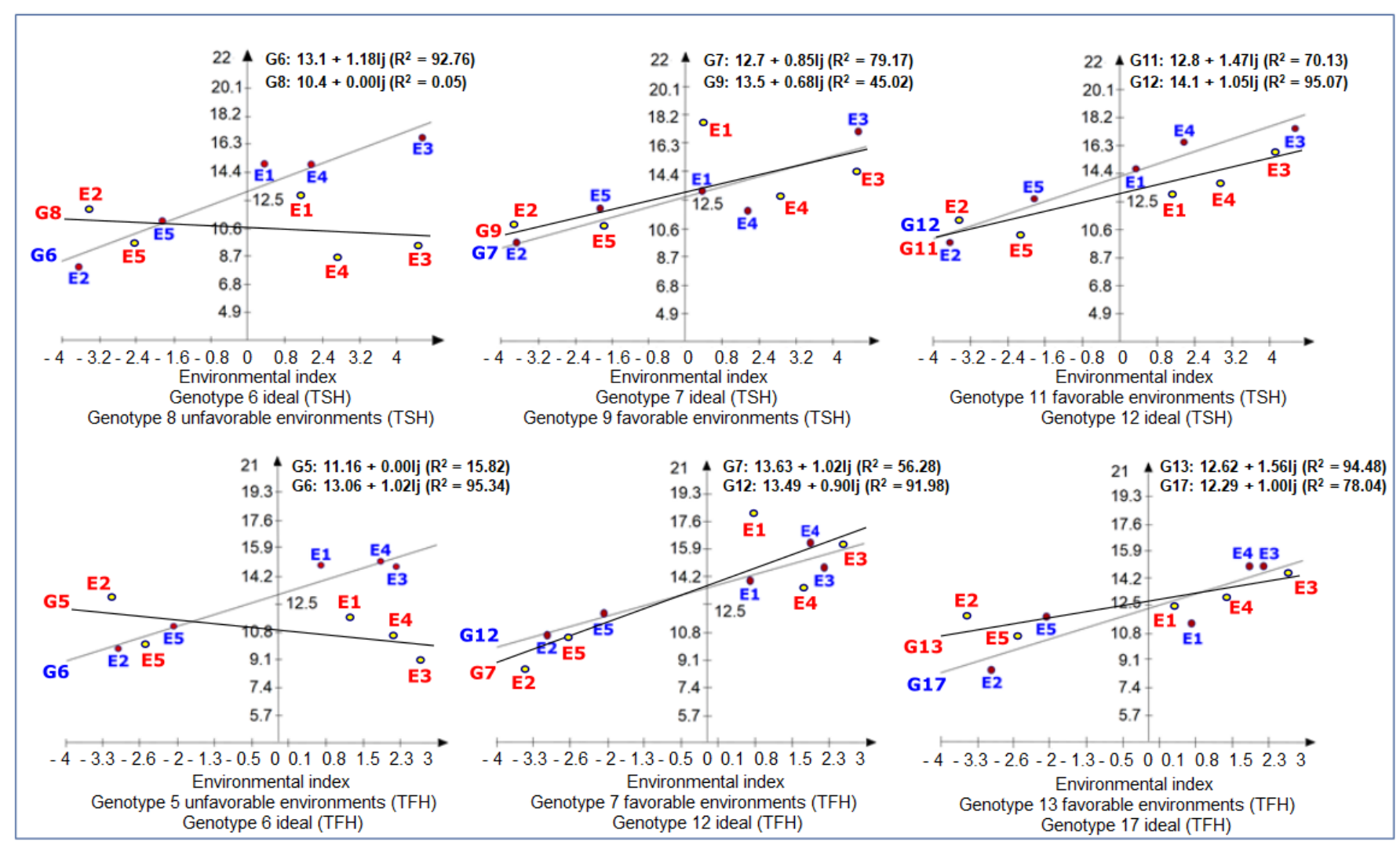

Figure 3. Average performance of ideal genotypes, genotypes for favorable and infavorable environments for the traits TSH and TFH in function of the environmental index and the regression line adjusted by Eberhart-Russel method.

Genotypes 9,14,15, and 18 showed specific adaptability to favorable environments and low stability; in this case, they are recommended for the micro regions of the North 
Coast, South Coast and South Forest where the incidence of rainfall occurred in sufficient quantity for the development of sugarcane-sugar as raw material (Table 1) [38]. This did not occur in the North Forest and Central Region microregions.

These genotypes also have low stability, which implies their use in agricultural areas that follow the model of intensive agriculture, characterized by the adoption of technologies such as irrigation and various types of inputs, in order to increase productivity. These are materials whose use must be judicious, since, being cultivated in environments of low technological level or subject to edaphoclimatic variations, their yield may be severely compromised [43-45]. Genotype 8 has specific adaptability to unfavorable environments (Figure 3).

As for fiber productivity per hectare (TFH), genotypes 6, 12, and 17 are ideal (Figure 3 ). Genotypes 7, 9, 15, and 18 have specific adaptability to favorable environments and low stability, thus following the same recommendations described above. Genotype 5 has specific adaptability to unfavorable environments (Figure 3).

It is important to note that it was not possible to identify genotypes with higher productivity, allocated to higher groups by the Scott and Knott test [30], and adapted to unfavorable environments. It is then questioned whether genotypes 11,16 , and 17 , which stood out in terms of sugar productivity, and genotypes 11,13,14, and 16, which stood out in terms of fiber productivity, could be recommended for unfavorable environments because, in addition to being adapted to favorable environments, they showed high stability. The centroid method provided interesting results allowing a correct conclusion in this regard.

\subsubsection{Centroid Method}

The centroid method also classified the sugarcane microregions of the state of Pernambuco as in the method of Eberhart and Russel [19] (Table 6).

Developed by Rocha et al. [21] and modified by Nascimento et al. [33], the centroid method initially uses the main component technique not to assess genetic divergence between genotypes, but to assess the differential performance of genotypes in a group of environments represented in a few axes on a two-dimensional graph [46].

The main components were obtained using the linear combination of environmental information in order to retain the maximum amount of information in terms of the total variation contained in the original data (Table 9).

Table 9. Estimates of eigenvalues and cumulative percentage of variance explained by the main components of the original data referring to the agro-industrial performance (TSH and TFH) of 20 sugarcane genotypes evaluated in the five microregions of the state of Pernambuco.

\begin{tabular}{cccccc}
\hline & TSH & & \multicolumn{2}{c}{ TFH } \\
\hline$\lambda_{\mathbf{j}}$ & $\lambda_{\mathbf{j}} \mathbf{( \% )}$ & $\begin{array}{c}\lambda_{\mathbf{j}} \mathbf{( \% )} \\
\text { Accumulated }\end{array}$ & $\lambda_{\mathbf{j}}$ & $\lambda_{\mathbf{j}} \mathbf{( \% )}$ & $\begin{array}{c}\lambda_{\mathbf{j}}(\mathbf{\%}) \\
\text { Accumulated }\end{array}$ \\
\hline 2.66 & 53.31 & 53.31 & 2.58 & 51.76 & 51.76 \\
1.45 & 29.16 & 82.47 & 1.63 & 32.76 & 84.48 \\
0.60 & 12.05 & 94.52 & 0.48 & 9.70 & 94.17 \\
0.21 & 4.24 & 98.72 & 0.23 & 4.64 & 98.82 \\
0.06 & 1.23 & 100.00 & 0.05 & 1.17 & 100.00 \\
\hline
\end{tabular}

It can be seen that the first two main components retained a percentage greater than $80 \%$ of the variation originally contained in the original data. The creation of twodimensional graphs to assess the adaptability and stability of genotypes in terms of productivity (TSH and TFH), in the five microregions, can be done using only the two main components (MC1 and MC2) [47].

The classification of the genotypes in terms of adaptability and stability was made by comparing the values of the Cartesian distance of the genotypes in relation to the seven reference points in the graph (ideotypes or control genotypes). (Figure 1). 
To facilitate the classification of the genotypes, the inverse of the distance value between the genotypes and the seven ideotypes was used, as was the probability of each genotype belonging to each group (Tables 10 and 11).

Table 10. Estimates of sugar productivity, classification of sugarcane genotypes in one of the seven groups proposed by the modified centroid method and probability associated with the classification of each genotype.

\begin{tabular}{|c|c|c|c|c|c|c|c|c|c|}
\hline Genotypes & Average & Group & $\mathrm{I}(\mathbf{P b})$ & $\mathrm{II}(\mathbf{P b})$ & $\mathrm{III}(\mathbf{P b})$ & IV(Pb) & $\mathrm{V}(\mathbf{P b})$ & $\mathrm{VI}(\mathrm{Pb})$ & $\mathrm{VII}(\mathbf{P b})$ \\
\hline 1 & $11.28 \mathrm{~b}$ & $\mathrm{~V}$ & 0.08 & 0.08 & 0.16 & 0.12 & 0.27 & 0.08 & 0.22 \\
\hline 2 & $12.01 \mathrm{~b}$ & $\mathrm{~V}$ & 0.09 & 0.07 & 0.11 & 0.09 & 0.30 & 0.09 & 0.24 \\
\hline 3 & $9.7 \mathrm{~b}$ & III & 0.08 & 0.08 & 0.22 & 0.20 & 0.18 & 0.08 & 0.16 \\
\hline 4 & $8.71 b$ & IV & 0.07 & 0.07 & 0.15 & 0.36 & 0.15 & 0.07 & 0.12 \\
\hline 5 & $10.74 b$ & III & 0.08 & 0.07 & 0.24 & 0.14 & 0.19 & 0.08 & 0.19 \\
\hline 6 & $13.1 \mathrm{a}$ & $\mathrm{V}$ & 0.12 & 0.11 & 0.08 & 0.07 & 0.31 & 0.14 & 0.18 \\
\hline 7 & $12.7 \mathrm{a}$ & $\mathrm{V}$ & 0.10 & 0.08 & 0.09 & 0.08 & 0.30 & 0.10 & 0.26 \\
\hline 8 & $10.41 \mathrm{~b}$ & III & 0.09 & 0.09 & 0.21 & 0.16 & 0.19 & 0.09 & 0.17 \\
\hline 9 & $13.5 \mathrm{a}$ & $\mathrm{V}$ & 0.14 & 0.11 & 0.10 & 0.08 & 0.21 & 0.14 & 0.21 \\
\hline 10 & $11.91 \mathrm{~b}$ & $\mathrm{~V}$ & 0.09 & 0.08 & 0.13 & 0.10 & 0.26 & 0.09 & 0.24 \\
\hline 11 & $12.87 \mathrm{a}$ & VII & 0.07 & 0.05 & 0.09 & 0.06 & 0.19 & 0.07 & 0.47 \\
\hline 12 & $14.18 \mathrm{a}$ & $\mathrm{V}$ & 0.17 & 0.11 & 0.08 & 0.07 & 0.21 & 0.16 & 0.21 \\
\hline 13 & $11.78 b$ & $\mathrm{~V}$ & 0.09 & 0.11 & 0.08 & 0.10 & 0.35 & 0.11 & 0.14 \\
\hline 14 & $13.5 \mathrm{a}$ & VI & 0.15 & 0.16 & 0.08 & 0.09 & 0.18 & 0.20 & 0.15 \\
\hline 15 & $12.61 \mathrm{a}$ & $\mathrm{V}$ & 0.13 & 0.15 & 0.09 & 0.10 & 0.22 & 0.16 & 0.15 \\
\hline 16 & $14.67 \mathrm{a}$ & VI & 0.18 & 0.15 & 0.06 & 0.05 & 0.12 & 0.32 & 0.11 \\
\hline 17 & $12.19 \mathrm{a}$ & $\mathrm{V}$ & 0.11 & 0.12 & 0.09 & 0.10 & 0.30 & 0.13 & 0.16 \\
\hline 18 & $13.46 a$ & VI & 0.15 & 0.17 & 0.08 & 0.08 & 0.18 & 0.19 & 0.14 \\
\hline 19 & $11.8 \mathrm{~b}$ & $\mathrm{~V}$ & 0.11 & 0.16 & 0.09 & 0.12 & 0.24 & 0.14 & 0.14 \\
\hline 20 & $11.51 b$ & $\mathrm{~V}$ & 0.08 & 0.09 & 0.09 & 0.10 & 0.39 & 0.10 & 0.15 \\
\hline
\end{tabular}

$\mathrm{Pb}$ : probability. Phenotypic average followed by the same letter in the column belong to the same group by the Scott and Knott test at $5 \%$ probability. The average values are the same presented in Table 5 , correspond to the average of the genotypes $\left(\beta_{\theta}\right)$ by the methodology of Eberhart and Russel.

Table 11. Estimates of fiber productivity, classification of sugarcane genotypes in one of the seven groups proposed by the modified centroid method and probability associated with the classification of each genotype.

\begin{tabular}{|c|c|c|c|c|c|c|c|c|c|}
\hline Genotypes & Averages & Group & $\mathrm{I}(\mathrm{Pb})$ & $\mathrm{II}(\mathrm{Pb})$ & $\mathrm{III}(\mathbf{P b})$ & $\mathrm{IV}(\mathrm{Pb})$ & $\mathrm{V}(\mathbf{P b})$ & $\mathrm{VI}(\mathrm{Pb})$ & $\mathrm{VII}(\mathrm{Pb})$ \\
\hline 1 & $12.05 \mathrm{~b}$ & $\mathrm{~V}$ & 0.08 & 0.07 & 0.13 & 0.09 & 0.29 & 0.08 & 0.26 \\
\hline 2 & $11.69 b$ & $\mathrm{~V}$ & 0.07 & 0.07 & 0.12 & 0.10 & 0.36 & 0.08 & 0.20 \\
\hline 3 & $10.14 b$ & III & 0.08 & 0.07 & 0.25 & 0.17 & 0.18 & 0.08 & 0.16 \\
\hline 4 & $8.79 b$ & IV & 0.06 & 0.07 & 0.16 & 0.38 & 0.14 & 0.07 & 0.11 \\
\hline 5 & $11.16 \mathrm{~b}$ & III & 0.08 & 0.07 & 0.27 & 0.12 & 0.18 & 0.08 & 0.19 \\
\hline 6 & $13.06 \mathrm{a}$ & $\mathrm{V}$ & 0.09 & 0.07 & 0.07 & 0.06 & 0.38 & 0.10 & 0.22 \\
\hline 7 & $13.63 a$ & V & 0.14 & 0.11 & 0.10 & 0.08 & 0.22 & 0.15 & 0.20 \\
\hline 8 & $11.07 \mathrm{~b}$ & $\mathrm{~V}$ & 0.09 & 0.08 & 0.18 & 0.14 & 0.23 & 0.09 & 0.20 \\
\hline 9 & $14.06 a$ & VII & 0.15 & 0.09 & 0.10 & 0.08 & 0.20 & 0.14 & 0.25 \\
\hline 10 & $11.98 \mathrm{~b}$ & VII & 0.09 & 0.07 & 0.15 & 0.10 & 0.24 & 0.09 & 0.27 \\
\hline 11 & $13.07 a$ & VII & 0.07 & 0.05 & 0.08 & 0.05 & 0.19 & 0.06 & 0.51 \\
\hline 12 & $13.49 \mathrm{a}$ & $\mathrm{V}$ & 0.11 & 0.08 & 0.08 & 0.07 & 0.28 & 0.11 & 0.28 \\
\hline 13 & $12.62 a$ & V & 0.11 & 0.12 & 0.09 & 0.09 & 0.30 & 0.13 & 0.16 \\
\hline 14 & $13.51 \mathrm{a}$ & $\mathrm{V}$ & 0.15 & 0.15 & 0.08 & 0.08 & 0.20 & 0.19 & 0.15 \\
\hline 15 & $12.82 \mathrm{a}$ & $\mathrm{V}$ & 0.13 & 0.15 & 0.10 & 0.10 & 0.21 & 0.16 & 0.16 \\
\hline 16 & $14.89 \mathrm{a}$ & VI & 0.20 & 0.15 & 0.06 & 0.06 & 0.12 & 0.30 & 0.11 \\
\hline 17 & $12.29 \mathrm{a}$ & V & 0.09 & 0.08 & 0.10 & 0.09 & 0.35 & 0.09 & 0.20 \\
\hline 18 & $13.05 a$ & $\mathrm{~V}$ & 0.14 & 0.16 & 0.09 & 0.09 & 0.20 & 0.17 & 0.15 \\
\hline 19 & $11.17 \mathrm{~b}$ & V & 0.10 & 0.14 & 0.11 & 0.15 & 0.23 & 0.13 & 0.14 \\
\hline 20 & $11.8 \mathrm{~b}$ & $\mathrm{~V}$ & 0.08 & 0.08 & 0.09 & 0.09 & 0.41 & 0.09 & 0.15 \\
\hline
\end{tabular}

$\mathrm{Pb}$ : probability. Phenotypic average followed by the same letter in the column belong to the same group by the Scott and Knott test at $5 \%$ probability. The average values are the same presented in Table 5 , correspond to the average of the genotypes $\left(\beta_{\theta}\right)$ by the methodology of Eberhart and Russel. 
Regarding sugar productivity (TSH), genotypes $6,7,15$, and 17 have a general adaptability and belong to the "a" group with the highest productivity by the Scott and Knott test [30], therefore they are recommended for all of the microregions.

It was previously questioned whether genotypes 11,16 , and 17 could be recommended in unfavorable environments, as they showed high stability by the method of Eberhart and Russel [19]. Genotype 11 has medium adaptability to unfavorable environments, and genotype 17, as previously seen, has average general adaptability, so we conclude that they can be. They can be recommended for the North Forest and Central Region microregions classified as unfavorable. Genotypes 9 and 12 have the same probability of belonging to the group with average general adaptability and to the group with average adaptability to unfavorable environments. It is important at this point to highlight that genotype 12 is the standard cultivar RB92579, the most widely planted in the state of Pernambuco due to its wide adaptability, high productivity, and tolerance to stress due to water deficit. Therefore, it is not surprising that other genotypes are recommended in more than one environment. Finally, genotypes 14,16 , and 18 showed medium adaptability to favorable environments.

For fiber productivity (TFH), genotypes $6,7,12,13,14,15,17$, and 18 show medium general adaptability. It was also asked whether genotypes $11,13,14$, and 16 could be recommended for unfavorable environments. Genotypes 13 and 14 do, because they have medium general adaptability and genotype 11 medium adaptability to unfavorable environments, so these can be recommended for the North Forest and Central Region microregions. Genotype 9 has medium adaptability to unfavorable environments and genotype 16 has medium adaptability to favorable environments. Genotype 4 was classified, in both productivity traits, as poorly adapted, suggesting its disposal.

The concept of adaptability and stability in the centroid method differs from the others because the genotype of maximum specific adaptation is not the one that performs well in groups of favorable and unfavorable environments, but the genotype that presents maximum values for a given group of environments (favorable and unfavorable) and minimum for the other group [21]. It is important to add to this statement by Rocha et al. [21] that, in the case of the modified centroid method, genotypes of medium adaptability to specific environments are those that present average values in their performance. This means, according to Moura et al. [48], that unlike the method of Eberhart and Russel [19], which uses few classes of adaptability to group the genotypes, the modified centroid method allows greater flexibility in the classification.

\subsubsection{AMMI Method}

The AMMI reveals that the sugarcane microregions are contrasting environments and that the genotypes present differential performances in these cultivation sites [49].

The AMMI method combines a univariate analysis of the additive effects of the genotypes with the multiplicative effect of the $G \times E$ interaction. In this multiplicative effect of the interaction, a multivariate analysis of the main components is performed, decomposing the effects of the interaction into singular values [50].

In the analysis presented in Table 7, the sum of the squares was decomposed into four main component axes (IPCA), where only the first was significant, capturing $75 \%, 31 \%$ and $74 \%, 30 \%$ of the interaction in relation to TSH and TFH respectively. This result is highly satisfactory and greater than those obtained by Guerra et al. [51] and Antunes et al. [8] for the cultivation of sugarcane.

One of the requirements of the AMMI analysis is that in the first axis of main components (IPCA1), there is a higher standard uptake due to the effects of the $\mathrm{G} \times \mathrm{E}$ interaction. As the number of selected axes increases, the percentage increases "noise" that is the additional residue of unpredictable and uninterpretable responses, which can reduce the predictive power of the analysis [52-54]. In the present work, being the first significant axis and accumulating more than $70 \%$ of the accumulated variance, the AMMI1 biplot graph is sufficient to classify genotypes and describe the interaction with high predictive power [51]. The AMMI analysis is among the most used, because it allows for the best 
decomposition of $\mathrm{G} \times \mathrm{E}$ interaction, including showing which genotypes in a given group of experiments most contribute to accentuating it [52].

The analysis of the AMMI biplot graph is quite simple, the abscissa represents the main effects that would be the general average of TSH and TFH of the tested genotypes, and the ordinate the first axis of the interaction (IPCA 1). The lower the IPCA value in the genotype, the lower its contribution to the $G \times E$ interaction and, consequently, the material will be more stable. The classification of genotypes as to adaptability must be made by observing the quadrants of the graph and the scores for each pair of genotypes and environments, if they present the same sign interact positively, and if they have opposite signs, negatively [55].

Looking closely at Figure 2a, genotypes 6, 7, and 12 are ideal, as they have higher sugar productivity and can be recommended for all microregions, since they are closer to the zero line of the IPCA1 axis. It is important to highlight that in the centroid method genotypes 6, 7, and 12 showed average general adaptability, that is, they presented good agroindustrial performance in all evaluated micro-regions. As the AMMI analysis allows an efficient $\mathrm{G} \times \mathrm{E}$ decomposition, even showing the genotypes that contributed more and less to the interaction, it can be said that the agreement between the methodologies in question gives greater security to the breeder in the recommendation of the genotypes.

Genotypes 9 and 11 are adapted to the North Coast (E1) microregion, classified as favorable by the centroid and Eberhart and Russel [19] methods. Genotypes 14, 15, 16, 17, and 18 show adaptability to the South Forest microregion, also classified as favorable.

Regarding the TFH, Figure 2b, genotypes 6 and 12 were classified as ideal. Genotypes 7,9 , and 11 are adaptable to the North Coast microregion, and genotypes 13,14, 15, 16, 17, and 18 are adaptable to the South Coast and South Forest microregions, respectively. It is important to show that genotype 3 has specific adaptability to the Central Region, but shows low productivity, categorized as constituting a lower group by the Scott and Knott test [30]. Genotype 4 has the lowest productivity and has been classified as poorly adapted and once again it is recommended to be discarded.

\subsubsection{Mixed Models Method}

The mixed model methodology classifies the genotypes in adaptability and stability based on the harmonic average of the relative performance of the predicted genotypic values (MHPRVG). It is a measure of easy interpretation allowing to select simultaneously for productivity, adaptability, and stability [56].

The genotypes with MHPRVG $\geq 1$ are those with the greatest adaptability and stability, the amount of MHPRVG*MG refers to MHPRVG multiplied by the general average of all environments, providing, therefore, the average genotypic value of each genotype penalized by instability and capitalized by adaptability [22].

The results presented in Table 8 show that genotypes 12,16, 9, 11, 6, 14, 7, and 18 have higher predicted genotypic values for sugar and fiber productivity per hectare, adaptability, and stability. Genotype 4 has the lowest predicted genotypic value, low adaptability, and low stability.

According to Torres et al. [57], the mixed model methodology: allows for considering correlated errors within locations, as well as stability and adaptability in the selection of superior genotypes; provides genetic values already discounted from instability; and can be applied to any number of environments. In addition, this methodology generates results in the unit or scale of the evaluated trait, which can be directly interpreted as genetic values, which the other methods do not allow.

For this reason, the methodology of mixed linear models is considered an optimal method of selection and several authors have verified its superiority, when compared to other methodologies for the analysis of adaptability and stability, in several cultures, such as carrot [58], rice [59], and sugarcane [10].

Evaluating 25 winter rapeseed genotypes in different environments via mixed models, Bocianowski and Liersh [60], identified materials with high harmonic averages (high geno- 
typic adaptability and stability), and pointed out the mixed models as a potential selection method for the inclusion of new materials breeding programs. In the present work, the efficiency of the mixed model methodology is notorious, however it should be remembered that it is a method of predicting the actual genetic values of the genotypes with specific accuracy. This methodology can indicate whether the phenotypic averages of the traits that were used in the other methodologies to classify the genotypes in terms of adaptability and stability have a greater genetic component than the influence of environmental variations (interactions). Looking closely all data presented, there is great agreement in the classification and recommendation of genotypes by the methodologies used.

However, genotypes 13,15 , and 17 that were recommended for favorable environments, in reality must undergo more careful management, as they have MHPRVG $<1$. Therefore, further experimentation with these materials is recommended.

It is understood that there is no one best methodology, but instead the best methodology is that which best fits the needs of the breeder. In the present work, which deals with the evaluation of a group of improved genotypes that have already undergone several selection cycles for the traits TSH, FP, SP, and TFH, and are phenotypically very similar, the methodologies used were necessary to accurately discriminate these materials in terms of productivity, adaptability, and stability. The methodologies of Eberhart and Russel, centroid, and AMMI were complementary in the classification and the mixed model methodology was used to validate the recommendation of the genotypes.

\section{Conclusions}

Genotypes 6,7, 9, 14, 16, and 18 stand out in terms of the productivity of sugar and fiber, with high potential to be released as commercial cultivars.

The methodologies were complementary and efficient in the classification of genotypes in terms of productivity, adaptability, and stability.

Author Contributions: Conceptualization, J.d.A.D.F. and T.C.J.; methodology, J.d.A.D.F., F.G.-S. and M.C.F.; software, J.d.A.D.F., G.R.M. and A.L.P.d.S.; validation, L.S.S., R.G.d.L. and A.d.S.S.; formal analysis, M.C.d.C.S., A.C.F.P. and C.C.R.d.B.; investigation, M.L.L.d.C., O.H.d.O. and A.E.P.S.; resources, L.S.S., R.G.d.L., A.d.S.S. and F.A.C.S.; data curation, J.d.A.D.F., F.G.-S., G.R.M. and M.C.F.; writing - original draft preparation, M.L.L.d.C., O.H.d.O. and A.E.P.S.; writing—review and editing, J.d.A.D.F., T.C.J. and F.A.C.S.; visualization, M.C.d.C.S., F.P, A.C.F.P. and C.C.R.d.B.; supervision, T.C.J.; project administration, J.d.A.D.F.; All authors have read and agreed to the published version of the manuscript.

Funding: This research received no external funding.

Institutional Review Board Statement: Not applicable.

Informed Consent Statement: Not applicable.

Data Availability Statement: Data sharing not applicable.

Acknowledgments: We thank Djalma Euzébio Simões Neto for kindly allowing us use the genotypes of the PMGCA/UFRPE/RIDESA.

Conflicts of Interest: The authors declare no conflict of interest.

\section{References}

1. Rodrigues, J.A.R. From the mill to a biorefinery. The sugar factory as an industrial enterprise for the generation of biochemicals and biofuels. Quim. Nova 2011, 34, 1242-1254. [CrossRef]

2. Pitarelo, A.P.; Silva, T.A.D.; Peralta-Zamora, P.G.; Ramos, L.P. Effect of moisture content in the steam treatment and enzymatic hydrolysis of sugarcane bagasse. Quim. Nova 2012, 35, 1502-1509. [CrossRef]

3. Clemente, P.R.; Santos, L.A.; Gomes, V.S.; Souza, J.E.; Barboza, A.S. Potential energy of cane sugar in a biomass plant sugarcane. Rev. Univ. Vale Rio Verde 2016, 14, 1101-1108.

4. de Oliveira, M.H.R.; Sousa, A.E.C.; de Oliveira, R.S.; Aguas, M.A.; da Silva Ávila, E.A.; da Silva, W.R.; do Couto, C.A. Management of waste after harvesting sugarcane in the cerrado: Use of strawing versus economic contribution. Braz. J. Dev. 2020, 6, 3406-3421. [CrossRef] 
5. Silveira, L.C.I.D.; Brasileiro, B.P.; Kist, V.; Weber, H.; Daros, E.; Peternelli, L.A.; Barbosa, M.H.P. Selection in energy cane families. Crop Breed. Appl. Biotechnol. 2016, 16, 298-306. [CrossRef]

6. Fernandes, A.R.; de Azeredo, A.A.C.; de Oliveira, R.A.; Bespalhok Filho, J.C.; Ido, O.T.; Daros, E.; Brasileiro, B.P. Agricultural performance and genetic parameters for yield-related traits of sugar-and energy cane families derived from planned crosses. Genet. Mol. Res. 2017, 16. [CrossRef]

7. Da Silva, J.W.; Soares, L.; Ferreira, P.V.; da Silva, P.P.; da Silva, M.J.C. Canonical correlations of agro-industrial characteristics in sugarcane. Acta Sci. Agron. 2007, 29, 345-349.

8. Antunes, W.R.; Schöffel, E.R.; Silva, S.D.D.A.; Eicholz, E.; Härter, A. Adaptability and phenotypic stability of sugarcane clones. Pesqui. Agropecu. Bras. 2016, 51, 142-148. [CrossRef]

9. Iwańska, M.; Paderewski, J.; Stępień, M.; Rodrigues, P.C. Adaptation of Winter Wheat Cultivars to Different Environments: A Case Study in Poland. Agronomy 2020, 10, 632. [CrossRef]

10. de Paula, T.M.; Marinho, C.D.; Souza, V.; Barbosa, M.H.P.; Peternelli, L.A.; Kimbeng, C.A.; Zhou, M.M. Relationships between methods of variety adaptability and stability in sugarcane. Genet. Mol. Res. 2014, 13, 4216-4225. [CrossRef]

11. Lavorenti, N.A.; Matsuoka, S. Combination parametric and non-parametric methods for stability analysis of sugarcane cultivars. Pesqui. Agropecu. Bras. 2001, 36, 653-658. [CrossRef]

12. Murakami, D.M.; Cardoso, A.A.; Cruz, C.D.; Bizão, N. Some considerations about two methodologies for stability and adaptability analysis. Cienc. Rural 2004, 34, 71-78. [CrossRef]

13. Carvalho, I.R.; Szareski, V.J.; Silva, J.A.G.D.; Nunes, A.C.P.; Rosa, T.C.D.; Barbosa, M.H.; Souza, V.Q.D. Multivariate best linear unbiased predictor as a tool to improve multi-trait selection in sugarcane. Pesqui. Agropecu. Bras. 2020, 55, e00518. [CrossRef]

14. Mariotti, J.A.; Oyarzabal, E.S.; Osa, J.M.; Bulacio, A.N.R.; Almada, G.H. Análisis de estabilidad y adaptabilidad de genótipos de caña de azucar. I. Interacciones dentro de una localidad experimental. Rev. Agron. Noroeste Argent. 1976, 13, $105-127$.

15. Becker, H.C. Correlations among some statistical measures of phenotypic stability. Euphytica 1981, 30, 835-840. [CrossRef]

16. Squilassi, M.G. Interação de Genótipos com Ambientes; Embrapa Tabuleiros Costeiros: Aracajú, Brasil, 2003 ; pp. $20-21$.

17. Pupin, S.; De Araújo Dos Santos, A.V.; Zaruma, D.U.G.; Miranda, A.C.; Da Silva, P.H.M.; Marino, C.L.; De Moraes, M.L.T. Produtividade, estabilidade e adaptabilidade em progênies de polinização aberta de Eucalyptus urophylla ST Blake. Sci. For. 2015, 43, 127-134.

18. Vencovsky, R.; Barriga, P. Genética Biométrica no Fitomelhoramento; Sociedade Brasileira de Genética: Ribeirão Preto, Brasil, 1992; pp. 200-262.

19. Eberhart, S.T.; Russell, W.A. Stability parameters for comparing varieties. Crop Sci. 1966, 6, 36-40. [CrossRef]

20. Borém, A.; Miranda, G.V. Melhoramento de Plantas, 6th ed.; Editora UFV: Viçosa, Brasil, 2013; pp. 148-149.

21. Rocha, R.B.; Muro-Abad, J.I.; Araújo, E.F.; Cruz, C.D. Evaluation of the centroid method for study of environment adaptability of clones of Eucalyptus grandis. Ciência Florest. 2005, 15, 255-266. [CrossRef]

22. Resende, M.D.V. Sistema Estatístico e Seleção Genética Computadorizada via Modelos Lineares Mistos; Embrapa Florestas: Colombo, Brasil, 2007; pp. 72-75.

23. Pereira, A.S.; Shitsuka, D.M.; Parreira, F.J.; Shitsuka, R. Metodologia da Pesquisa Científica, 1st ed.; UFSM, NTE: Santa Maria, Brasil, 2018; pp. 65-73.

24. Koffler, N.F. Caracterização Edafo-Climática das Regiões Canavieiras do Brasil: Pernambuco, 1st ed.; IAA-PLANALSUCAR: Piracicaba, Brasil, 1986; pp. 1-78.

25. Fernandes, A. Cálculos na Agroindústria da Cana de Açúcar, 3rd ed.; STAB: AÇÚCAR, ÁLCOOL E SUBPRODUTOS: Piracicaba, Brasil, 2003; pp. 1-416.

26. Finlay, K.W.; Wilkinson, G.N. The analysis of adaptation in a plant-breeding programme. Aust. J. Agric. Res. 1963, 14, 742-754. [CrossRef]

27. Cruz, C.D.; Carneiro, P.C.S.; Regazzi, A.J. Modelos Biométricos Aplicados ao Melhoramento Genético, 3rd ed.; Editora UFV: Viçosa, Brasil, 2014; pp. 436-507.

28. Zobel, R.W.; Wright, M.J.; Gauch, H.G., Jr. Statistical analysis of a yield trial. Agron. J. 1988, 80, 388-393. [CrossRef]

29. Gollob, H.F. A statistical model which combines features of factor analytic and analysis of variance techniques. Psychometrika 1968, 33, 73-115. [CrossRef] [PubMed]

30. Scott, A.J.; Knott, M. A cluster analysis method for grouping means in the analysis of variance. Biometrics 1974, 507-512. [CrossRef]

31. Cruz, C.D. Genes: A software package for analysis in experimental statistics and quantitative genetics. Acta Sci. Agron. 2013, 35, 271-276. [CrossRef]

32. R Development Core Team. R: A Language and Environment for Statistical Computing. 2014. Available online: http://www.Rproject.org (accessed on 15 February 2021).

33. Nascimento, M.; Cruz, C.D.; Campana, A.C.M.; Tomaz, R.S.; Salgado, C.C.; Ferreira, R.D.P. Alteration of the centroid method to evaluate genotypic adaptability. Pesqui. Agropecu. Bras. 2009, 44, 263-269. [CrossRef]

34. Regis, J.A.V.B.; Andrade, J.A.D.C.; Santos, A.D.; Moraes, A.; Trindade, R.W.R.; Henriques, H.J.R.; Oliveira, L.C. Adaptability and phenotypic stability of sugarcane clones. Pesqui. Agropecu. Bras. 2018, 53, 42-52. [CrossRef]

35. Seife, A.; Tena, E. Genotype x environment interaction and yield stability analysis of sugarcane (Saccharum officinarum L.) genotypes. Int. J. Adv. Res. Biol. Sci. 2020, 7, 14-26. [CrossRef] 
36. Silveira, L.C.I.D.; Kist, V.; Paula, T.O.M.D.; Barbosa, M.H.P.; Oliveira, R.A.D.; Daros, E. Adaptabilidade e estabilidade fenotípica de genótipos de cana-de-açúcar no estado de Minas Gerais. Cienc. Rural 2012, 42, 587-593. [CrossRef]

37. Mattos, P.H.C.D.; Oliveira, R.A.D.; Bespalhok Filho, J.C.; Daros, E.; Veríssimo, M.A.A. Evaluation of sugarcane genotypes and production environments in Paraná by GGE biplot and AMMI analysis. Crop Breed. Appl. Biotechnol. 2013, 13, 83-90. [CrossRef]

38. Inman-Bamber, N.G.; Smith, D.M. Water relations in sugarcane and response to water deficits. Field Crops Res. 2005, 92, 185-202. [CrossRef]

39. Pedrozo, C.A.; Barbosa, M.H.P.; Resende, M.D.V.; Peternelli, L.A.; Costa, P.M.A.; Silva, F.L. Selection efficiency at the initial phases in sugarcane improvement. Rev. Ceres 2008, 55, 1-8.

40. Garcia, C.H.; Nogueira, M.C.S. The application of the REML/BLUP methodology for eucalypt clones selection. Sci. For. 2005, $68,107-112$.

41. Tew, T.L.; Cobill, R.M. Genetic Improvement of Sugarcane (Saccharum spp.) as an Energy Crop. In Genetic Improvement of Bioenergy Crops; Vermerris, W., Ed.; Springer: New York, NY, USA, 2008; pp. 273-294.

42. Dias, F.T.C.; Pitombeira, J.B.; Teófilo, E.M.; de Sousa Barbosa, F. Adaptability and phenotypic stability to the character in grain yield varieties of soybeans for the State of Ceará. Cienc. Agron. 2009, 40, 129-134.

43. Verissimo, M.A.A.; Oliveira, R.A.D.; Daros, E.; Härter, A. Genetic parameters and performance of sugarcane families under cold stress in the South of Brazil. Pesqui. Agropecu. Bras. 2018, 53, 583-592. [CrossRef]

44. Peluzio, J.M.; Afférri, F.S.; Monteiro, F.J.F.; Melo, A.V.D.; Pimenta, R.S. Adaptability and stability of soybean cultivars under conditions of varzeas, in Tocantins State Brazil. Cienc. Agron. 2010, 41, 427-434. [CrossRef]

45. Bornhofen, E.; Benin, G.; Storck, L.; Woyann, L.G.; Duarte, T.; Stoco, M.G.; Marchioro, S.V. Statistical methods to study adaptability and stability of wheat genotypes. Bragantia 2017, 76, 1-10. [CrossRef]

46. Amorin, B.S.; Souza, G.I.; Silveira, M.A.; Nascimento, I.R.; Ferreira, T.A. Phenotypic adaptability of sweet potato genotypes from of botanical seeds in the region Southern Tocantins State. Appl. Res. Agrotechnol. 2011, 4, 31-50.

47. Barros, H.B.; Sediyama, T.; Teixeira, R.D.C.; Fidelis, R.R.; Cruz, C.D.; Reis, M.S. Stability and adaptability of soybean genotypes tested in the sate of Mato Grosso. Rev. Ceres 2010, 57, 359-366. [CrossRef]

48. Moura, W.D.M.; Oliveira, A.M.C.; Gonçalves, D.R.; Carvalho, C.F.M.D.; Oliveira, R.L.D.; Cruz, C.D. Adaptability and stability of organic-grown arabica coffee production using the modified centroid method. Crop Breed. Appl. Biotechnol. 2017, 17, 359-365. [CrossRef]

49. Silveira, L.C.I.D.; Kist, V.; Paula, T.O.M.D.; Barbosa, M.H.P.; Peternelli, L.A.; Daros, E. AMMI analysis to evaluate the adaptability and phenotypic stability of sugarcane genotypes. Sci. Agric. 2013, 70, 27-32. [CrossRef]

50. Maia, M.C.C.; Vello, N.A. Adaptability and stability of soybean experimental lines selected for agronomic traits and insect resistance by uni-multivariate method. Bragantia 2006, 65, 215-226. [CrossRef]

51. Guerra, E.P.; de Oliveira, R.A.; Daros, E.; Zambon, J.L.C.; Ido, O.T.; Bespalhok Filho, J.C. Stability and adaptability of early maturing sugarcane clones by AMMI analysis. Crop Breed. Appl. Biotechnol. 2009, 9, 206-267. [CrossRef]

52. Gauch, H.G., Jr. Statistical analysis of yield trials by AMMI and GGE. Crop Sci. 2006, 46, 1488-1500. [CrossRef]

53. Crossa, J.; Gauch, H.G., Jr.; Zobel, R.W. Additive main effects and multiplicative interaction analysis of two international maize cultivar trials. Crop Sci. 1990, 30, 493-500. [CrossRef]

54. Oliveira, A.B.D.; Duarte, J.B.; Pinheiro, J.B. Application of AMMI analysis in the assessment of yield stability in soybean. Pesqui. Agropecu. Bras. 2003, 38, 357-364. [CrossRef]

55. Melo, L.C.; Melo, P.G.S.; Faria, L.C.D.; Diaz, J.L.C.; Del Peloso, M.J.; Rava, C.A.; Costa, J.G.C.D. Interaction with environment and stability of common bean genotypes in the South Centre Region of Brazil. Pesqui. Agropecu. Bras. 2007, 42, 715-723. [CrossRef]

56. Bastos, I.T.; Barbosa, M.H.P.; de Resende, M.D.V.; Peternelli, L.A.; da Silveira, L.C.I.; Donda, L.R.; de Figueiredo, I.C.R. Evaluation of genotype versus environmentinteraction in sugarcane using mixed models. Pesqui. Agropecu. Trop. 2007, 37, 195-203.

57. Torres, F.E.; Teodoro, P.E.; Sagrilo, E.; Ceccon, G.; Correa, A.M. Genotype x environment interaction in semiprostrade cowpea genotypes via mixed models. Bragantia 2015, 74, 255-260. [CrossRef]

58. Silva, G.O.D.; Carvalho, A.D.F.D.; Vieira, J.V.; Benin, G. Verification of the adaptability and stability of carrot populations by AMMI, GGE Biplot and REML/BLUP methods. Bragantia 2011, 70, 494-501. [CrossRef]

59. Bueno, L.G.; Vianello, R.P.; Rangel, P.H.N.; Utumi, M.M.; Cordeiro, A.C.C.; Pereira, J.A.; Brondani, C. Adaptability and stability of accessions of a rice core collection. Pesqui. Agropecu. Bras. 2012, 47, 216-226. [CrossRef]

60. Bocianowski, J.; Liersch, A. Multi-environmental evaluation of winter oilseed rape genotypic performance using mixed models. Euphytica 2021, 217, 1-9. [CrossRef] 